US Army Corps

of Engineers .

Prepared for the U.S. Army Corps of Engineers, Portland District,

under an Interagency Agreement with the U.S. Department of Energy

Contract DE-AC05-76RL01830

\title{
Columbia River Channel Improvement Project Rock Removal Blasting: Monitoring Plan
}

\section{Final Plan}

TJ Carlson

GE Johnson

January 2010

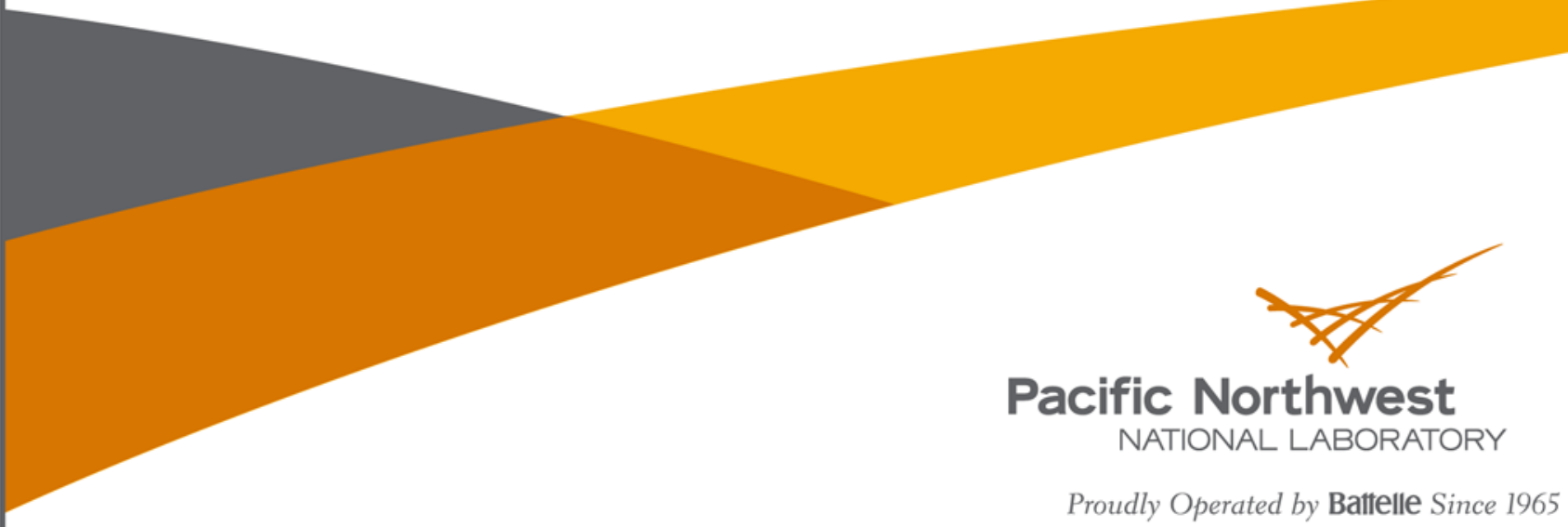




\title{
DISCLAIMER
}

This report was prepared as an account of work sponsored by an agency of the United States Government. Neither the United States Government nor any agency thereof, nor Battelle Memorial Institute, nor any of their employees, makes any warranty, express or implied, or assumes any legal liability or responsibility for the accuracy, completeness, or usefulness of any information, apparatus, product, or process disclosed, or represents that its use would not infringe privately owned rights. Reference herein to any specific commercial product, process, or service by trade name, trademark, manufacturer, or otherwise does not necessarily constitute or imply its endorsement, recommendation, or favoring by the United States Government or any agency thereof, or Battelle Memorial Institute. The views and opinions of authors expressed herein do not necessarily state or reflect those of the United States Government or any agency thereof.

\author{
PACIFIC NORTHWEST NATIONAL LABORATORY \\ operated by \\ BATTELLE \\ for the \\ UNITED STATES DEPARTMENT OF ENERGY \\ under Contract DE-AC05-76RL01830
}

Printed in the United States of America

Available to DOE and DOE contractors from the

Office of Scientific and Technical Information,

P.O. Box 62, Oak Ridge, TN 37831-0062;

ph: (865) 576-8401

fax: $(865)$ 576-5728

email: reports@adonis.osti.gov

\footnotetext{
Available to the public from the National Technical Information Service, U.S. Department of Commerce, 5285 Port Royal Rd., Springfield, VA 22161 ph: (800) 553-6847 fax: $(703) 605-6900$

email: orders@ntis.fedworld.gov

online ordering: http://www.ntis.gov/ordering.htm
}

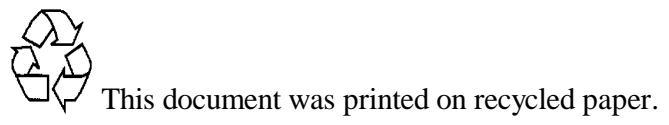




\section{Columbia River Channel Improvement Project Rock Removal Blasting: Monitoring Plan}

\section{Final Plan}

TJ Carlson

GE Johnson

January 2010

Prepared for

the U.S. Army Corps of Engineers, Portland District, under an Interagency Agreement with

the U.S. Department of Energy

Contract DE-AC05-76RL01830

Pacific Northwest National Laboratory

Richland, Washington 99352 


\section{Foreword}

This study was funded as part of the Columbia River Channel Improvement Project managed by the U.S. Army Corps of Engineers (USACE). The study was conducted by the Pacific Northwest National Laboratory (PNNL) for the USACE Portland District, whose technical lead was Blaine Ebberts (1-503-808-4763). The PNNL project manager was Thomas Carlson (1-503-417-7562, Thomas.Carlson@pnl.gov). The final version of this document is a project deliverable (PNNL Project No. 57948). 


\section{Acronyms and Abbreviations}

\begin{tabular}{ll} 
AFEP & Anadromous Fish Evaluation Program \\
CDB & Contract Drilling \& Blasting LLC \\
cfs & cubic feet per second \\
CRCIP & Columbia River Channel Improvement Project \\
d & day(s) \\
dB & decibel(s) \\
EL & elevation \\
fps & feet per second \\
ft & foot/feet \\
h & hour(s) \\
kcfs & thousand cubic feet per second \\
kHz & kilohertz \\
m & meter(s) \\
min & minute(s) \\
msl & mean sea level \\
NMFS & National Marine Fisheries Service \\
PNNL & Pacific Northwest National Laboratory \\
pps & pings per second \\
s & second(s) \\
SEL & sound exposure level \\
SPL & sound pressure level \\
$\mu$ Pa & micro-pascal \\
USACE & U.S. Army Corps of Engineers \\
USACE-NWP & U.S. Army Corps of Engineers, Northwestern Division \\
& \\
\hline &
\end{tabular}




\section{Contents}

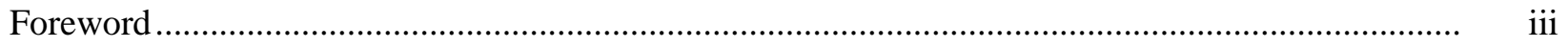

Acronyms and Abbreviations …............................................................................................

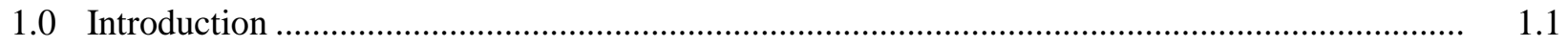

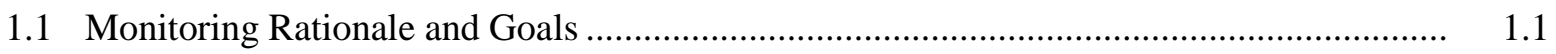

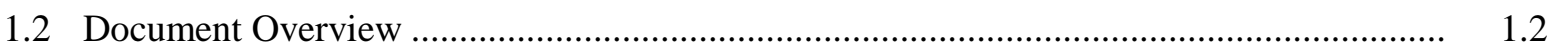

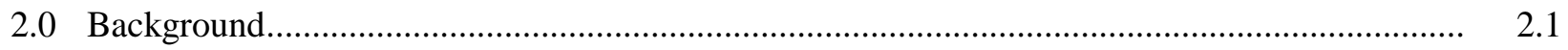

2.1 Monitoring Period, Goal, and Objectives.................................................................. 2.6

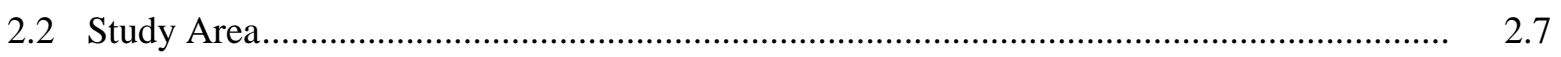

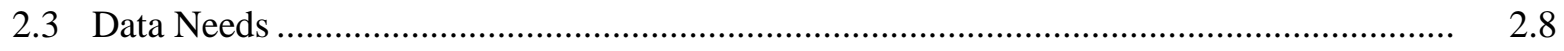

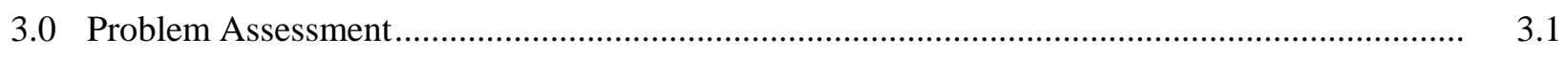

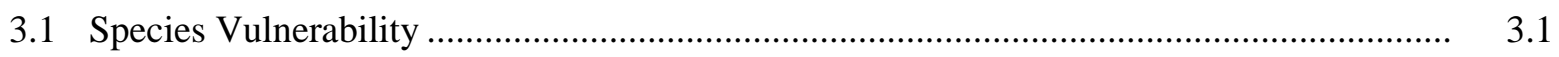

3.1.1 Marine Mammals ........................................................................................ 3.1

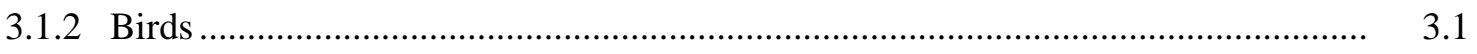

3.1.3 Salmon Adults and Juveniles ................................................................... 3.2

3.1.4 Eulachon Adults and Eggs .................................................................................. 3.3

3.1.5 White and Green Sturgeon .......................................................................... 3.5

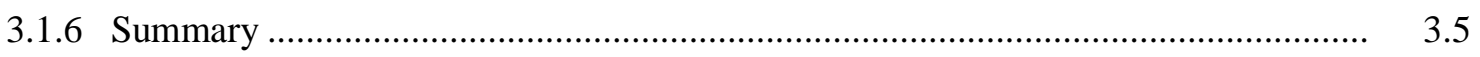

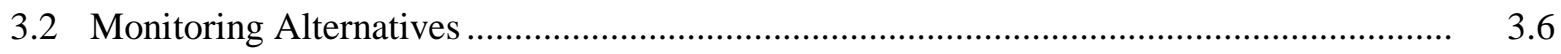

3.2.1 Physical Capture.......................................................................................... 3.7

3.2.2 Exposure-Response Assessment Techniques .................................................... 3.8

3.2.3 Monitoring Priorities ........................................................................................ 3.9

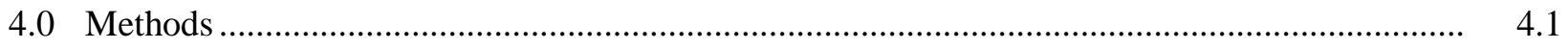

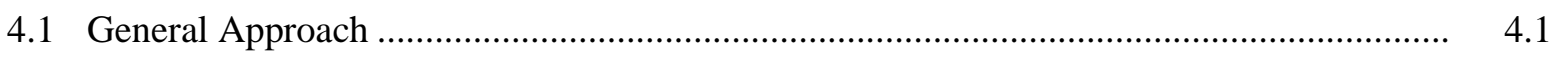

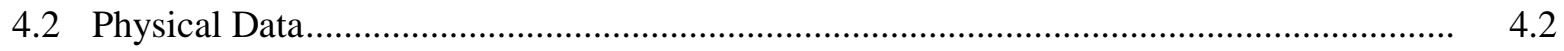

4.2.1 Blast Impulse Signals .................................................................................. 4.2

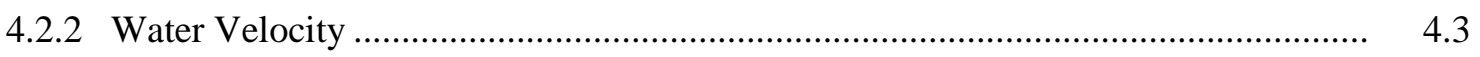

4.2.3 Summary and Sampling Design ..................................................................... 4.4

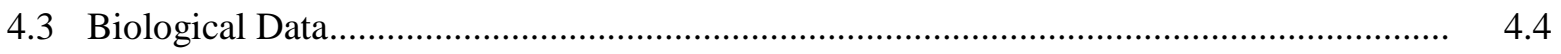

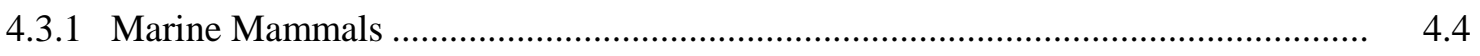

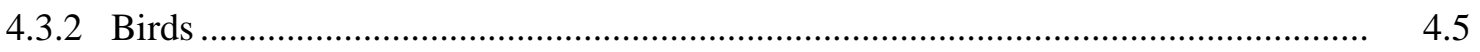

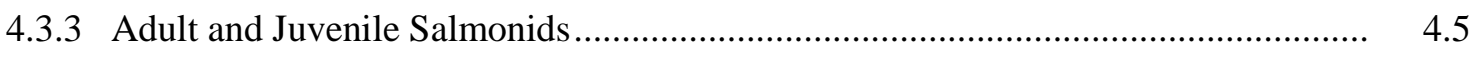

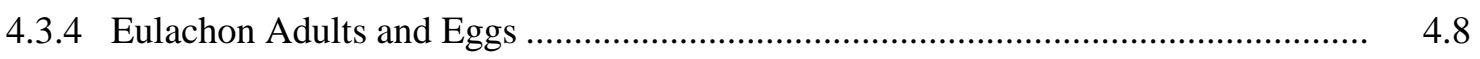

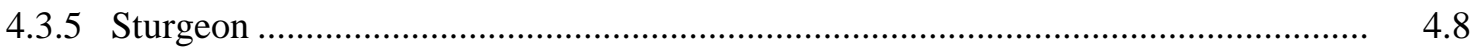

4.3.6 Summary and Sampling Design ..................................................................... 4.8

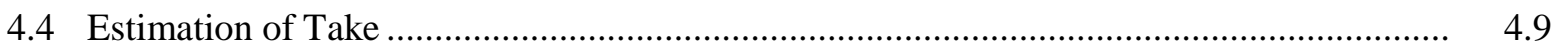


5.0 Data, Reporting, and Adaptive Management ................................................................

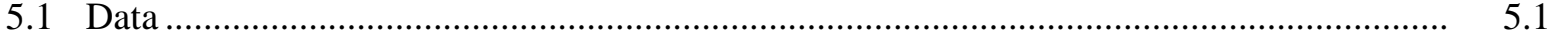

5.1.1 Response Variables ............................................................................... 5.1

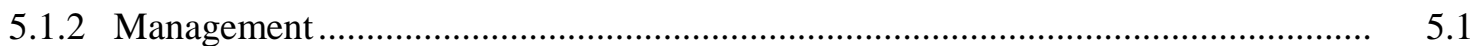

5.1.3 Quality Assurance ............................................................................................... 5.2

5.2 Communications and Reporting ................................................................................. 5.2

5.3 Adaptive Management ............................................................................................ 5.3

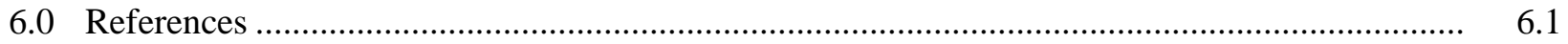

Appendix - Statistical Model for Estimating Take of ESA-Listed Species During Blasting in the Lower Columbia River. 


\section{Figures}

2.1 Log-Log Plot of the Estimated Peak Overpressure for Single-Charge Blasts by 60- and 90-lb Charges Imbedded in Bedrock as a Function of Range in Feet

from the Location of an Explosion

2.2 Relationship Between Impulse and Peak Overpressure for a 60-lb Charge as Estimated by Blasting Consultant Showing Linear Fit Between Impulse and Peak Pressure

2.3 Aerial View of the Mainstem of the Columbia River at Warrior Point near St. Helens, Oregon

2.4 Area Potentially Impacted by High-Energy Impulsive Overpressure Generated by Blast Events

2.5 Area Potentially Impacted by High-Energy Impulsive Overpressure Generated by Blasting

2.6 Project Site.

5.1 Communications Diagram

5.2 An Adaptive Management Process for Blasting....

\section{Tables}

2.1 Excerpts from the Biological Opinion for the Columbia River Channel Improvement Project.

3.1 Proportions 2002-2008 BON Mean Daily Counts Summed over Month(s) ............................. 3.4

3.2 Likelihood of Species Presence in the Impact Area ...............................................................

3.3 Monitoring Alternatives for Biological Data .......................................................................... 3.6

3.4 Priorities for Biological Monitoring - Approximate Monitoring Periods and Methods ............. 3.9

4.1 Monitoring Equipment and Deployment Techniques for Physical Data .................................... 4.4

4.2 Sampling Design - Monitoring Locations and Frequencies for Physical Data .......................... 4.4

4.3 Monitoring Equipment and Deployment Techniques for Biological Data ............................... 4.8

4.4 Sampling Design - Monitoring Locations and Frequencies for Biological Data ........................ 4.9

5.1 Template for a Summary Data Table - Response Variables by Component and Blast Event 


\subsection{Introduction}

This document provides a monitoring plan to evaluate take as outlined in the National Marine Fisheries Service 2002 Biological Opinion for underwater blasting to remove rock from the navigation channel for the Columbia River Channel Improvement Project. The plan was prepared by the Pacific Northwest National Laboratory (PNNL) for the U.S. Army Corps of Engineers (USACE), Portland District.

\subsection{Monitoring Rationale and Goals}

The USACE must remove a rock formation to reach project depth for the Columbia River Channel Improvement Project (CRCIP). Removal of rock will require blasting to fracture the rock. A section of basalt between river miles 87 and 88 near St. Helens, Oregon, must be blasted and then dredged. The blasting will occur between November 1, 2009, and February 28, 2010, or until blast operations cease, and will create between 250,000 and 500,000 $\mathrm{yd}^{3}$ of material to dredge. Two blast events per day, one in early morning and one in the afternoon, are planned. For more details, see the operational blasting plan. ${ }^{1}$ The USACE has consulted with the federal and state resource agencies to perform this work at a time and in a manner that will minimize the potential for injury to fish and other animals of concern that may be present when blasting takes place. The USACE has agreed to conduct monitoring to assess any "take" of fish listed as endangered under the Endangered Species Act of 1973 (ESA) that may be exposed to the high-energy underwater impulses generated by blasting activity, as stipulated in the CRCIP Biological Opinion (NMFS 2002).

The species, numbers, distribution, and behavior of listed fish and other fish and animals of concern that may move through or be resident within the river volume that may be impacted are uncertain and potentially highly variable during the rock removal period. In addition to these factors, the difficulty of working in a large river adds complexity to monitoring actions.

The work for monitoring to meet Biological Opinion requirements will be performed in two phases. In Phase 1, a monitoring plan was designed in consultation with the USACE and submitted for review and approval by the regulatory agencies. In Phase 2, monitoring will be conducted and documented. The monitoring period will extend from November 1, 2009, through February 28, 2010, or until blast operations cease. The goals of the monitoring are to obtain biological response data during the test blast phase of the project to assist with evaluation of production blasting designs and, during both test blasting and production blasting, estimate the take of listed fish exposed to high-energy acoustic impulses caused by blast events.

This document addresses the monitoring plan for the CRCIP. This document is a necessary element for application to relevant authorities for permits to perform the rock removal project.

\footnotetext{
${ }^{1}$ Columbia River Channel Improvement Project - Operational Blasting Plan, submitted to the U.S. Army Corps of Engineers, Portland District, in 2009 by Contract Drilling \& Blasting LLC, S.P. Case, and Aimone-Martin Associates, LLC.
} 


\subsection{Document Overview}

In support of the USACE, PNNL researchers reviewed the requirements for monitoring the blasting operations stipulated in the CRCIP Biological Opinion (NMFS 2002) as well as USACE calculations of likely impacts (Section 2). They then assessed the underwater environment, with emphasis on vulnerability of the indigenous species to effects of the operations. The assessment resulted in a prioritized list of biological monitoring periods and methods tailored to each species (Section 3). A general approach was defined for analyzing physical and biological data collected during the monitoring, as well as methods for acquisition and analysis of data to meet project monitoring goals and objectives defined in the original assessment (Section 4). Protocols for monitoring data collection, and reporting, as well as adaptive management strategies, are presented in Section 5. Section 6 provides a list of literature sources cited in this plan. 


\subsection{Background}

The USACE has agreed to conduct monitoring to assess any take of listed fish exposed to the highenergy underwater impulses generated by blasting activity, as stipulated in the CRCIP Biological Opinion (NMFS 2002; see excerpts in Table 2.1).

Table 2.1. Excerpts from the Biological Opinion for the Columbia River Channel Improvement Project (NMFS 2002)

Excerpt from Table 3.1, p. 13 (NMFS 2002):

\begin{tabular}{|l|l|l|}
\hline $\begin{array}{l}\text { Drilling and } \\
\text { Blasting }\end{array}$ & $\begin{array}{l}\text { Associated with channel construction at basalt } \\
\text { rock outcrops. Holes would be drilled in } \\
\text { underwater rock formation, and charges set to } \\
\text { create an implosion. }\end{array}$ & $\begin{array}{l}\text {-A blasting plan would be developed for } \\
\text { each site. }\end{array}$ \\
& $\begin{array}{l}\text {-Implosion rather than explosion. } \\
\text {-Over-pressure from blast less than ten } \\
\text { psi. }\end{array}$ \\
& $\begin{array}{l}\text {-Monitoring of blasts. } \\
\text {-Fish "hazing" employed before blast. } \\
\end{array}$ & $\begin{array}{l}\text {-Timing window of November 1- } \\
\text { February 28. }\end{array}$ \\
& \\
\hline
\end{tabular}

Excerpt from p. 42 (NMFS 2002):

One location (Warrior Rock, RM 87.3) may require one-time, in-water blasting. NMFS anticipates blasting could injure or kill salmonids within the blasting area. However, the proposed action minimizes potential direct effects by requiring a blasting plan, using an in-water work window of November 1 to February 28 when salmonid abundance is lowest, and reducing the associated pressure wave by creating an implosion. NMFS believes reducing implosioninduced over-pressure to less than ten psi will minimize blast-related impacts to salmonids. NMFS believes that development of a NMFS-approved monitoring plan, that ensures the proposed blasting measures are implemented, will be important to minimize any injury or death of ESA-listed salmonids during blasting activities.

Excerpt from p. 95 (NMFS 2002):

Blasting. NMFS believes that short-term incidental take, in the form of killing and injury from blasting is reasonably certain to occur during channel construction actions. However, based on the effects analysis in Chapter 6.0 of the $2001 \mathrm{BA}$, the Corps concluded that few, if any, ESA-listed salmonids are likely to be directly taken as a result of blasting actions. Therefore, NMFS limits the amount of allowable incidental take from the single blasting event to no more than ten adult ESA-listed salmonids and 50 juvenile ESA-listed salmonids. Incidental take occurring beyond these limits is not authorized by this consultation. 
The NMFS clarified the take of listed salmonids in September 2009, changing from 10 adult and 50 juvenile listed salmonids per blast event to the same numbers but for all blast events combined.

Figure 2.1 shows estimates for peak overpressures (pounds per square inch) as a function of range (feet) for the leading edge of sound signals to be generated by 60 - and 90-lb charge blast events. ${ }^{1}$ Also shown in Figure 2.1 are the peak overpressure (70 psi) and range (140 ft) criteria proposed by the blasting contractor (CDB 2009, p. 4.5), and the peak overpressure (10 psi) and range to this peak overpressure level (700 ft) from a blast event expected for the NMFS “minimum effect” criterion (NMFS 2002).

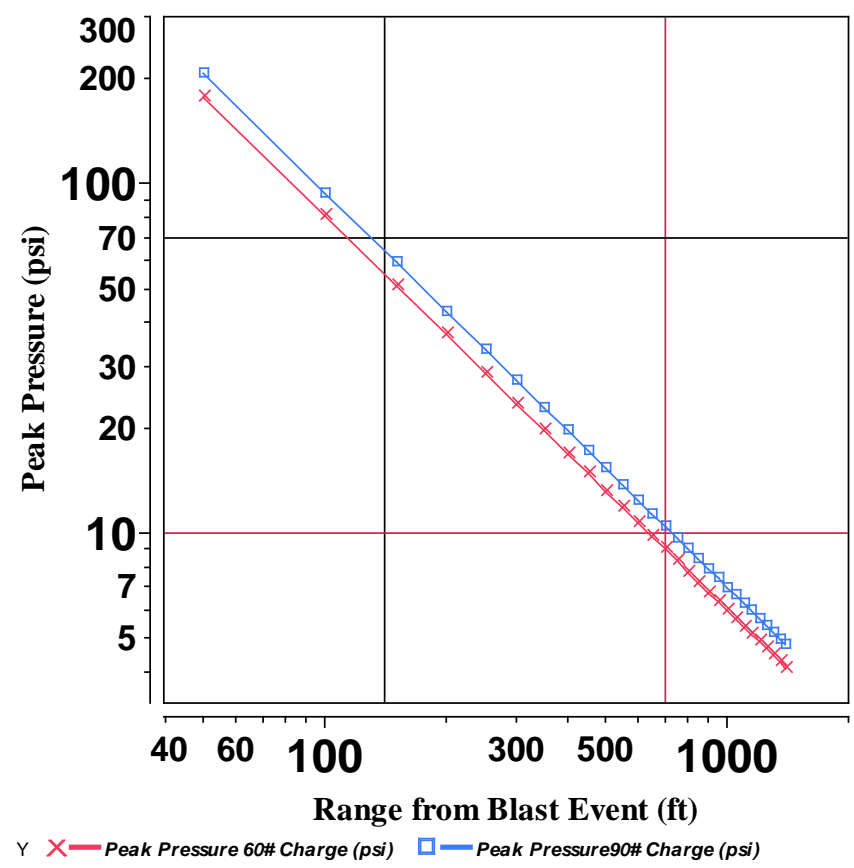

Figure 2.1. Log-Log Plot of the Estimated Peak Overpressure (in pounds per square inch) for SingleCharge Blasts by 60- and 90-lb Charges Imbedded in Bedrock as a Function of Range (in feet) from the Location of an Explosion. Peak overpressure estimates are from the USACENWP-provided Microsoft Excel spreadsheet, Columbia River Blast Pressure Impulse Attenuation Calculation R2.xls. Red horizontal and vertical lines show the NMFS "minimum effect” criterion (10 psi) and expected range of effect ( 700 ft). Black horizontal and vertical lines show the blasting contractor criterion for peak overpressure (70 psi) at a range (140 ft) from a blast event.

Figure 2.2 shows estimates of impulse as a function of peak overpressure. The high correlation between these metrics is a function of how they were estimated. ${ }^{1} \quad$ Figure 2.2 also shows the intersection of the blasting contractor and NMFS "no effect" peak overpressure criterion with the impulse-peak overpressure regression line.

\footnotetext{
${ }^{1}$ U.S. Army Corps of Engineers, North Pacific Division, Microsoft Excel Spreadsheet: Columbia River Blast Pressure Impulse Attenuation Calculation R2.xls.
} 


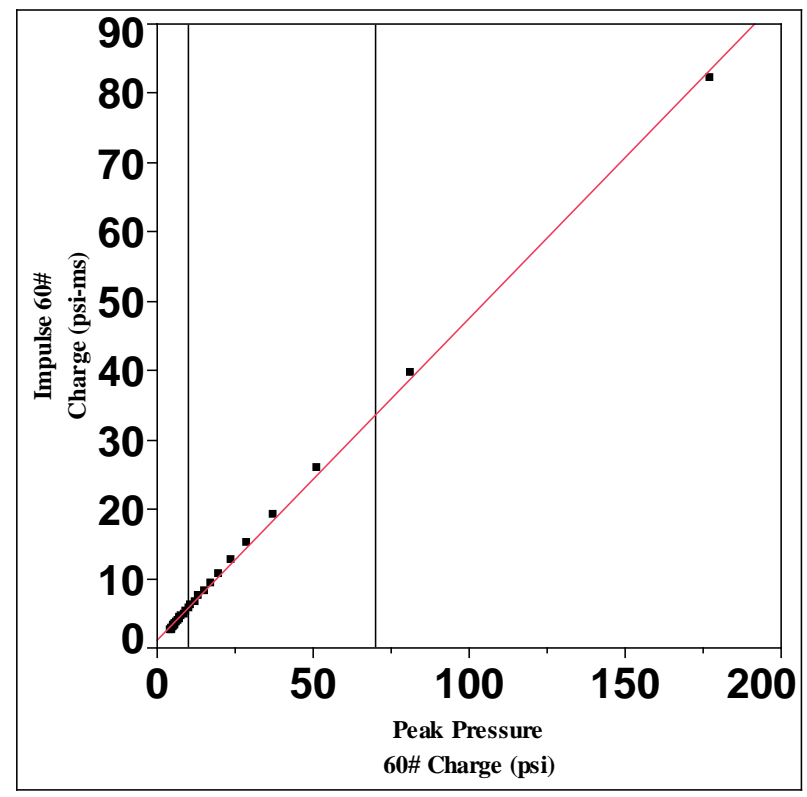

Figure 2.2. Relationship Between Impulse (in pounds per square inch per microsecond) and Peak Overpressure for a 60-lb Charge as Estimated by Blasting Consultant Showing Linear Fit Between Impulse and Peak Pressure. The R-squared value of the linear model fit to the data is 0.999. The Biological Opinion "minimum effect" exposure criterion of 10 psi peak overpressure and the blasting plan criterion of 70-psi peak pressure are shown as vertical reference lines..

The area projected to be impacted by blast-generated high-energy underwater sound impulses could extend across approximately 55\% of the river and for several hundreds of feet upstream and downstream of the location of explosions (Figures 2.3 through 2.5). The surface area of the estimated impact region is on the order of 35 acres. 


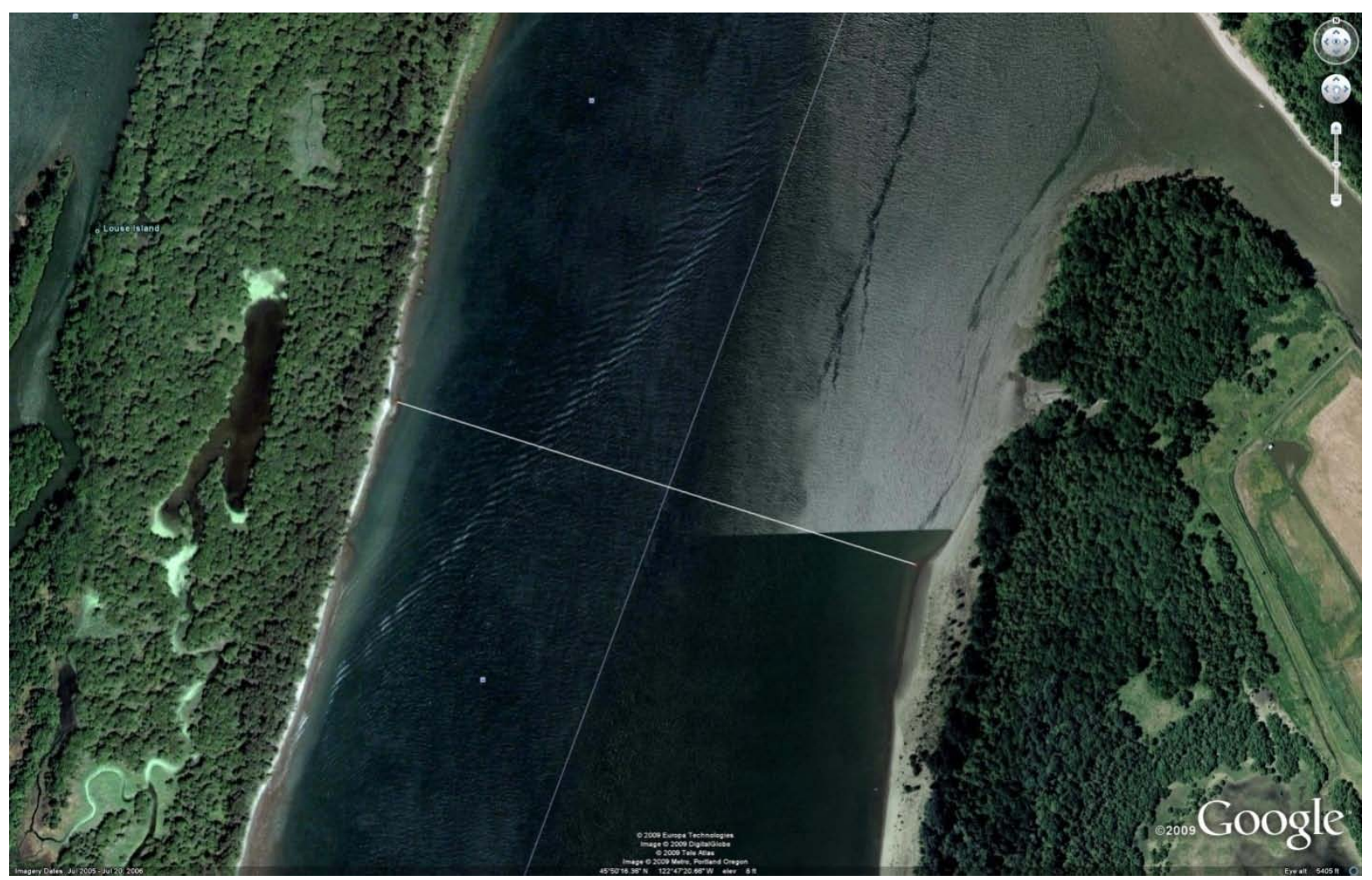

Figure 2.3. Aerial View of the Mainstem of the Columbia River at Warrior Point near St. Helens, Oregon. The width of the river at the line shown across the river is approximately 2,500 ft. Image copied from Google Earth. 


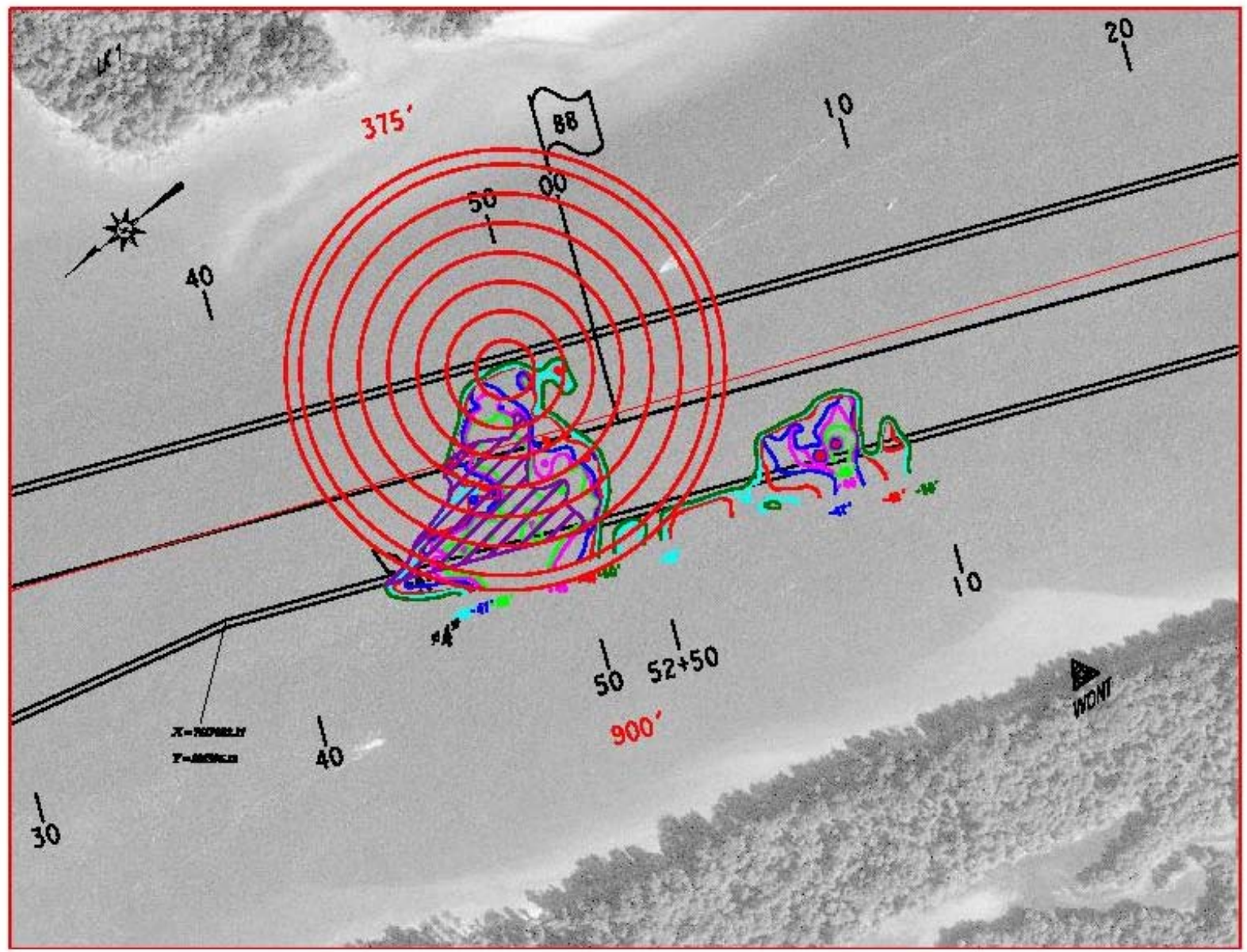

Figure 2.4. Area Potentially Impacted by High-Energy Impulsive Overpressure Generated by Blast Events. The contours shown are centered on the eastern-most section of the rock outcropping to be removed by blasting and extend out to the NMFS 10-psi peak overpressure "minimum effect" contour. Image provided by USACE-NWP. 


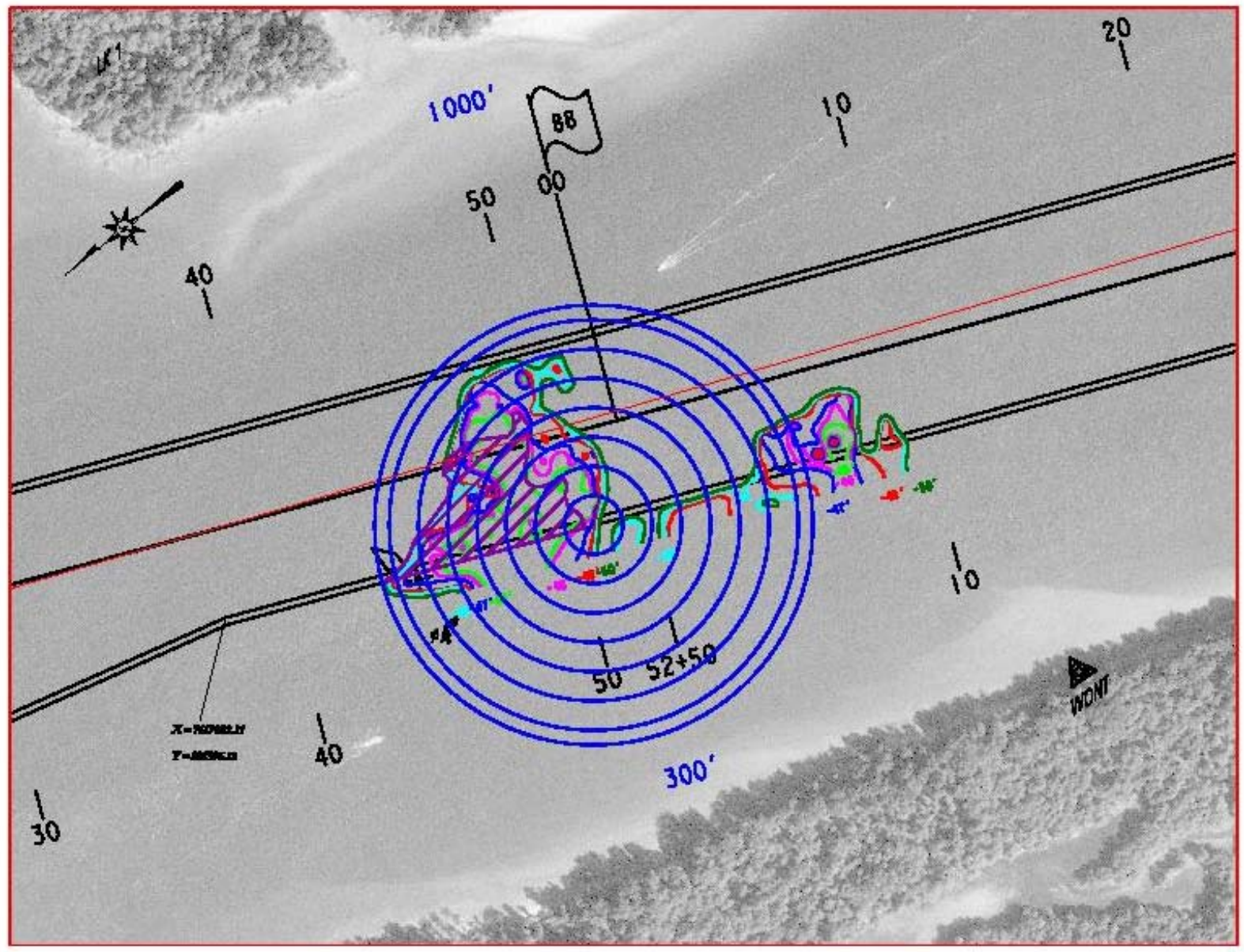

Figure 2.5. Area Potentially Impacted by High-Energy Impulsive Overpressure Generated by Blasting. The contours shown are centered on the western-most section of the rock outcropping to be removed by blasting and extend out to the NMFS 10-psi peak overpressure "minimum effect” contour. Image provided by USACE-NWP.

\subsection{Monitoring Period, Goals, and Objectives}

The monitoring period will be from November 1, 2009, through February 28, 2010, or until blast operations cease. The goals of monitoring are to obtain biological response data during the test blast and production blasting phases of the project to assist with evaluation of production blasting designs and, during test and production blasting, to estimate the take of listed fish exposed to high-energy acoustic impulses caused by blast events.

During production blasting, the objectives of monitoring are as follows:

- Prior to blast:

- Following completion of test blasting and until the onset of monitoring for juvenile fish or the end of blasting if this occurs prior to the initiation of monitoring for juvenile fish, estimate the flux of adult-size listed fish likely to occur within the impact area during a blast. 
- From the onset of juvenile monitoring until blasting is completed, estimate the flux of juvenilesize listed fish likely to occur within the impact area during a blast.

- After eulachon have been observed in the project area, estimate the number of adult eulachon likely to occur within the impact area during a blast and monitor for the occurrence of eulachon eggs in the project area.

- Estimate the number of juvenile and adult sturgeon likely to occur within the impact area during a blast.

- Survey a region that extends beyond the impact area (up to 2,000 $\mathrm{ft}$ from the blast event location) for the presence of marine mammals and protected birds and report their location to responsible parties prior to blasting.

- Following a blast:

- Survey the impact area and enumerate the number of dead fish, recover as many bodies as possible, and perform necropsies to determine cause of death on a subset of, or all, recovered bodies, depending on the number recovered.

- If eulachon are determined to be in the project area, sample eulachon eggs that may have been in the impact area and perform an examination to ascertain condition and potential effects from exposure to impulsive sound.

- Estimate the take of adult or juvenile listed fish as appropriate, given the focus of monitoring current at the time of the blast event.

\subsection{Study Area}

The study area is located between river miles 87 and 88 on the Columbia River near Warrior Point (Figure 2.6). Within the study area, the impact area is defined as the three-dimensional region in the river where the overpressure (positive or negative) caused by a blast event is equal to or greater than 10 psi. Ten psi is the "minimum effect" level identified by NMFS (NMFS 2002). The impact region most likely will vary from blast event to blast event, depending upon several factors. It is also expected that the impact region will not be symmetrical about the blast location, as indicated in Figures 2.4 and 2.5. 


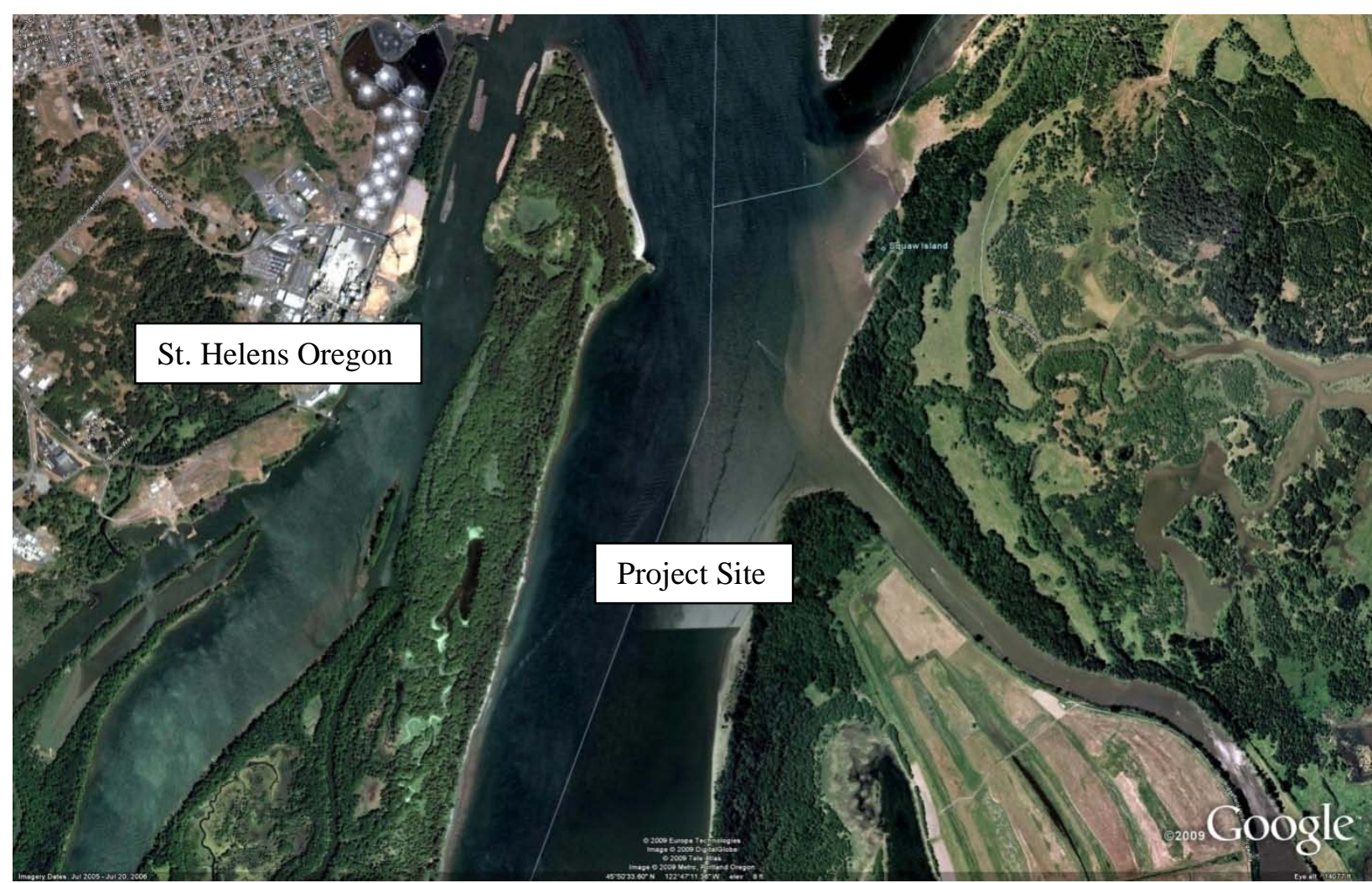

Figure 2.6. Project Site. At this location, the Columbia River runs approximately south to north with Oregon to the west and Washington to the east of the river. Image copied from Google Earth.

\subsection{Data Needs}

Data needs have been identified for the test blast period preceding production blasting and the production blasting monitoring period.

The blasting plan calls for testing of various blast charge configurations to identify the blast charge configuration that optimizes the volume of rock fractured per blast event while meeting the peak overpressure criterion of $70 \mathrm{psi}$ at a range of $140 \mathrm{ft}$ from the blast event. Data needs that must be addressed during this activity are

- the response of depth-acclimated juvenile hatchery Chinook salmon and rainbow trout to the production blast charge alternatives

- data required to estimate the take of listed species, as described in Section 3

Production blasting monitoring will need to address the following data needs:

- historical information for the likely abundance and distribution of marine mammals, protected birds, juvenile and adult salmon, both listed and not, and adult eulachon and eggs in the impact area between November 1 and February 28 
- data that will permit estimation of

- $\quad$ the number of listed and unlisted salmonids, sturgeon, and eulachon in the impact area prior to blasting

- $\quad$ the exposure of listed fish, unlisted salmonids, sturgeon, and eulachon to impulsive sound on a per blast basis

- the physiological response of listed fish, unlisted salmonids, sturgeon, and eulachon to impulsive sound

- estimation of the take of listed fish on a per-blast basis, based on data of their abundance and distribution, exposure to impulsive sound, and physiological response to impulsive sound exposure

- the velocity of water movement through the blast area

- protocols for classification of blast injury to eggs, juvenile, and adult fish

- monitoring methods that may permit physical capture of injured and dead animals from the impact area following each blast

- adult and juvenile salmonids

- adult and juvenile sturgeon

- eulachon adults and eggs

- monitoring methods that may permit non-physical assessment of injured and dead animals from the impact area following each blast

- listed and unlisted fish

- experimental designs that can use qualitative as well as quantitative measures to estimate take of listed fish. 


\subsection{Problem Assessment}

In this section, we assess the problem of environmental monitoring for the underwater blasting work. Problem assessment entails examining species vulnerability, followed by monitoring alternatives. Based on the assessment, the section closes with monitoring priorities.

\subsection{Species Vulnerability}

Marine mammals, diving birds, and fish exposed to high-energy impulsive underwater sound may be injured by percussion and/or impulsive decompression. The probability of injury or death, severity of injury, and type of injury varies with a number of biological and physical variables, including species, age, physical condition, physiological state, distance from the blast, and depth (hydrostatic pressure) at the time of exposure. The characteristics of the impulsive overpressure generated by the blast are a function of the type and quantity of explosive, where and how it is deployed, site characteristics such as bathymetry, and radial distance from the site of the explosion. The large number of exposure and response variables and the complex interaction between variables make it very difficult to accurately a priori predict the likely exposure of and consequence to exposed animals. However, some general rules of thumb are useful in the design of a blast monitoring plan, as discussed in the following paragraphs for marine mammals, diving birds, adult and juvenile salmonids, and eulachon adults and eggs.

\subsubsection{Marine Mammals}

The most likely injury to marine mammals at radial distances beyond the immediate blast area is either permanent or temporary hearing system impact. Detection of an impact is not easy for marine mammals, short of capture and detailed assessment of animal health or observations of significant changes in behavior, morbidity, or death. Deterrence is always the best policy with marine mammals, even if it means delay in the schedule of a blast. Criteria for the exposure of marine mammals to impulsive sound are available (Southall et al. 2008).

Marine mammals are not specifically identified as species of concern in the CRCIP Biological Opinion. However, avoidable and unnecessary complications to the project are likely to occur if blasting is permitted when any marine mammals are within range of probable impact. Therefore, the monitoring plan includes monitoring tasks to survey for marine mammals prior to blast and report their presence to the USACE. It is possible that protected marine mammals may be present in the impact area during the work period (NOAA 2008). If so, actions such as hazing may be taken by authorized personnel to remove marine mammals from an extended impact area or to keep them from entering prior to blasting. Special permitting and approved measures are required to remove (haze) marine mammals from regions of potential impact or to keep them from entering these regions prior to blasting.

\subsubsection{Birds}

Because of the high impedance barrier to sound transmission through the air-water interface, the risk to birds is very low, except for diving birds that may be underwater within the immediate vicinity of the blast at the time of blast. However, exposure of diving birds to impulsive underwater sound from an explosion would require millisecond timing on the part of the bird. As a consequence, the likelihood of 
such an exposure is considered to be very small, particularly if deterrence measures are taken if diving birds of concern are observed in the blast area.

As with marine mammals, birds are not identified as species of concern in the CRCIP Biological Opinion other than by broad-based language referring to "other" protected species. We have little information about the likelihood of occurrence of protected birds in the impact area during the work period. The likelihood of a bird being exposed to impulsive underwater sound appears to be very low. However, as is the case with marine mammals, unnecessary and avoidable complications to the project are likely to occur if protected birds are impacted. Again, as in the case of marine mammals, the monitoring plan includes monitoring tasks to survey for protected birds prior to blast and report their presence to responsible parties.

\subsubsection{Salmon Adults and Juveniles}

Both listed and unlisted juvenile and adult salmonids exposed to sound produced by blasting are at risk of barotrauma from both percussion and decompression. The relevant sound metrics needed to evaluate the risk of exposure are impulse, energy flux density, or sound exposure level (SEL) for percussion and the ratio of acclimation to exposure nadir pressures for decompression.

At short to intermediate ranges from the location of blasting where peak overpressure and impulse magnitudes are likely to be very high, both swim bladder and, to a considerably lesser extent, non-swim bladder fish are at risk of injury from percussion. The risk of injury is a function of characteristics of the overpressure impulse and fish size. A review of relevant literature is provided by Keevin and Hempen (1997). A relationship to estimate the "no-injury," 0.01, and 0.50 probabilities of mortality, given fish body mass ( 0.01 to $10,000 \mathrm{~g}$ ) and single-blast charge impulse ( 0.1 to $100 \mathrm{psi} / \mu \mathrm{s})$ is given by Yelverton et al. (1975). However, it is not clear at this time if any of the single-blast exposure stressor-response relationships for percussion in the literature, particularly for juvenile fish, are applicable to the multicharge and resulting complex multi-impulse sound exposures that will occur during test and production blasting during this project.

At radial locations out to ranges where negative overpressures are on the order of $60 \%$ of hydrostatic pressure, swim bladder fish are at a significantly higher risk of decompressive injury than are non-swim bladder fish (Goertner et al. 1994). When the ratio of static pressure to negative going overpressure is high, the risk of injury or death to depth-acclimated swim bladder fish is high. ${ }^{1}$ One implication of this is that swim bladder fish shallower in the water column (at lower hydrostatic pressure), all else being the same, will be less susceptible to decompressive injury that those at deeper depths. It is expected that because of the phase inversion that takes place when sound is reflected at the air-water interface, fish located very near the water surface will have a low risk of injury from percussion or decompression. In contrast, fish located at a depth corresponding to one-half the duration of an impulse or greater (on the order of $0.2 \mu \mathrm{s}$, or $\sim 1 \mathrm{ft}$ ) would potentially be at higher risk from both percussion and decompression. As is the case for percussive injury, it is not clear that the level of risk of decompressive injury from multiple exposures to negative overpressure (relative to static pressure) over a relatively short time is the same as a

\footnotetext{
${ }^{1}$ Carlson TJ, RS Brown, JR Skalski, and RL Townsend. Response of Juvenile Chinook Salmon to Rapid Decompression. Unpublished draft report to the U.S. Army Corps of Engineers, Portland District, in preparation by Pacific Northwest National Laboratory, Richland, Washington.
} 
single exposure. Salmonids have swim bladders, which, depending upon their physiological state at the time of exposure, makes them significantly more vulnerable to decompressive injury than fish without swim bladders (such as eulachon).

Both listed and unlisted juvenile and adult salmonids could be transiting the impact area during blast events. We do not have sufficient data to accurately estimate $a$ priori the numbers of juvenile and adult salmonids likely to be exposed to blasting. Based on adult passage counts at Bonneville and Willamette Falls dams, the greatest risk of exposure will be to chum salmon (Oncorhynchus keta) in November and December (Table 3.1). There also may be some Chinook salmon (O. tshawytscha) and steelhead (O. mykiss) in the area (Table 3.1). Estimation of take will require real-time assessment of the distribution (horizontal and vertical) and abundance of juvenile and/or adult salmonids in the impact area for each blast and development of the dose-response curve for probability of mortal injury.

Observations of adult chum passing Bonneville Dam from 1938 to 2009 indicate a wide range in dates of passage, daily passage and total annual passage. ${ }^{2}$ However, it is very clear from available data that the abundance of chum salmon has decreased since the late 1930s.

A review of available information shows that during November, December, and into January juvenile salmonids will not be actively migrating through the project area (Geist and Currie 2006; Friesen et al. 2007; Keller 2007; Tomaro et al. 2007, 2008; Johnson et al. 2008). However, juvenile fish may be present in the general vicinity of the project, using near shore areas for rearing. This information suggests that fish monitoring during November, December, and into January can focus on adult salmonids, transitioning to juvenile salmonids when emergence and migration of juvenile chum salmon has begun and when the occurrence of juvenile fish in the blast impact area becomes more likely.

\subsubsection{Eulachon Adults and Eggs}

Adult eulachon (Thaleichthys pacificus) do not have a swim bladder and are believed to become denser as they preferentially consume lighter weight oils and fat from their bodies to develop eggs and sperm and to provide energy for their upstream spawning migration (Phleger 1998). Rapid decompression is not expected to be a source of injury or mortality for adult eulachon. Percussion will be the primary injury mechanism and it is likely that these fish will only be injured if in close proximity to the blast source where peak overpressure and impulse are high. While animals very near the blast source may be carried to the surface with the bulk flow of water carried upward with explosion gasses and debris, most seriously injured or killed eulachon are more likely to sink downward and be passively transported with flow.

General descriptive information suggests that adult eulachon are not likely to occur in numbers until January (Romano et al. 2002a; NMFS 2008). At this time, we do not have historical data to accurately estimate a priori likely abundance, particularly given the large reduction in abundance in recent years and the highly variable abundance typical for these fish. General information predicting the relative strength of the 2010 eulachon spawning migration may be available from Oregon or Washington fisheries managers prior to initiation of blasting activity. Adults die soon after spawning, suggesting that dead

\footnotetext{
${ }^{2}$ http://www.cbr.washington.edu/cgi-bin/dart/dart?report=inventory_adult_years\&format $=$ standard \&proj=BON\&nab=fe.
} 
Table 3.1. Proportions 2002-2008 BON Mean Daily Counts Summed over Month(s). Data from www.fpc.org.

\begin{tabular}{|c|c|c|c|c|c|c|c|c|c|c|c|}
\hline \multicolumn{12}{|c|}{ Bonneville Dam } \\
\hline & Chin Adult & Chin Jack & Coho Adult & Coho Jack & Steelhead & Wild Steelhead & Sockeye & Pink & Chum & Lamprey & Shad \\
\hline Nov & $0.32 \%$ & $0.20 \%$ & $1.66 \%$ & $0.95 \%$ & $0.70 \%$ & $0.56 \%$ & $0.00 \%$ & $0.66 \%$ & $78.83 \%$ & $0.00 \%$ & $0.00 \%$ \\
\hline Dec & $0.02 \%$ & $0.00 \%$ & $0.03 \%$ & $0.00 \%$ & $0.20 \%$ & $0.16 \%$ & $0.00 \%$ & $0.00 \%$ & $11.62 \%$ & $0.00 \%$ & $0.00 \%$ \\
\hline Jan & $0.00 \%$ & $0.00 \%$ & $0.00 \%$ & $0.00 \%$ & $0.19 \%$ & $0.08 \%$ & $0.00 \%$ & $0.00 \%$ & $0.00 \%$ & $0.00 \%$ & $0.00 \%$ \\
\hline Feb & $0.00 \%$ & $0.00 \%$ & $0.00 \%$ & $0.00 \%$ & $0.17 \%$ & $0.07 \%$ & $0.00 \%$ & $0.00 \%$ & $0.00 \%$ & $0.00 \%$ & $0.00 \%$ \\
\hline Mar-Oct & $99.66 \%$ & $99.80 \%$ & $98.31 \%$ & $99.04 \%$ & $98.75 \%$ & $99.14 \%$ & $100.00 \%$ & $99.34 \%$ & $9.54 \%$ & $100.00 \%$ & $100.00 \%$ \\
\hline Total & 1 & 1 & 1 & 1 & 1 & 1 & 1 & 1 & 1 & 1 & 1 \\
\hline
\end{tabular}

\begin{tabular}{lrrrrr}
\hline \multicolumn{5}{c}{ Willamette Falls (dam) } \\
\hline \multirow{2}{*}{ Nov } & Chin Adult & Chin Jack & Coho Adult & Coho Jack & Steelhead \\
\cline { 2 - 6 } Dec & $0.02 \%$ & $0.07 \%$ & $5.50 \%$ & $3.01 \%$ & $0.47 \%$ \\
Jan & $0.00 \%$ & $0.00 \%$ & $0.31 \%$ & $0.04 \%$ & $1.22 \%$ \\
Feb & $0.00 \%$ & $0.00 \%$ & $0.01 \%$ & $0.00 \%$ & $3.51 \%$ \\
Mar-Oct & $0.00 \%$ & $0.00 \%$ & $0.00 \%$ & $0.00 \%$ & $8.27 \%$ \\
\hline Total & $99.98 \%$ & $99.93 \%$ & $94.18 \%$ & $96.95 \%$ & $86.52 \%$ \\
\hline
\end{tabular}


adult eulachon that spawned upstream of the project and expired following spawning may be present in the blast area. Necropsy may be required to correctly identify the cause of death for dead adult eulachon recovered following a blast. Estimation of take will require real-time assessment of the distribution and abundance of adult eulachon and eggs in the blast area.

Eulachon are broadcast spawners - eggs are carried downstream, developing enroute. Spawning takes place over sandy to small cobble bottoms (Howell et al. 2001). There is some speculation that the sticky eggs pick up grains of sand, becoming negatively buoyant, and are carried deeper in the water column (Howell et al. 2001). Eggs would begin to show in small numbers as early as February. Peak outmigration of eulachon larvae is generally in April (Ward 2002). The probability of injury to fish eggs is a strong function of their development stage and location relative to a blast event. Mechanical shock by blast impulse percussion is the potential injury mechanism of concern.

Decompression does not appear to be a potential injury mechanism for eggs under most exposure conditions for most species of fish. Eggs, because they generally lack inclusion of air bubbles, are likely to be resistant to injury by rapid decompression (Wright and Hopky 1998). However, during some development stages, eggs are very susceptible to injury by shock. Therefore, percussion is likely the impulsive sound exposure mechanism most likely to injure or kill fish eggs. Assessment of shock would require measuring acoustic particle velocity concurrent with the pressure component of the impulsive signals generated by blasting. Measurement of acoustic particle velocity is complicated and requires special equipment and deployment methods. Measurement of acoustic particle velocity is not planned.

\subsubsection{White and Green Sturgeon}

White sturgeon (Acipenser transmontanus) and green sturgeon (A. medirostris) are also species of concern. Green sturgeon are listed under the Endangered Species Act, but white sturgeon are not. Green sturgeon are not likely to be present in the study area during the blasting period (November through February). ${ }^{1}$ However, white sturgeon likely will be present as adults, sub-adults, and young-of-the-year during November through February, although abundances will be lower than those during other seasons of the year (Romano et al. 2002b).

\subsubsection{Summary}

Species vulnerability by month during the blasting period is summarized in Table 3.2. Monitoring will need to be conducted accordingly.

\footnotetext{
${ }^{1}$ T. Rien, Oregon Department of Fish and Wildlife, personal communication, September 17, 2009.
} 
Table 3.2. Likelihood of Species Presence in the Impact Area. Dark, light, and no shading imply high, moderate, and low probability of occurrence, respectively.

\begin{tabular}{|c|c|c|c|c|}
\hline Component & November & December & January & February \\
\hline \multicolumn{5}{|l|}{ Mammals (TBD) } \\
\hline \multicolumn{5}{|l|}{ Birds (TBD) } \\
\hline \multicolumn{5}{|c|}{ Salmon adults (TBD) } \\
\hline \multicolumn{5}{|l|}{ Salmon juveniles } \\
\hline \multicolumn{5}{|l|}{ Eulachon adults } \\
\hline \multicolumn{5}{|l|}{ Eulachon eggs } \\
\hline Sturgeon & & & & \\
\hline
\end{tabular}

\subsection{Monitoring Alternatives}

Other than making systematic observations of dead animals for the purposes of this study, there are no practical monitoring alternatives for marine mammals and diving birds like there are for fish. Two general monitoring alternatives for fishes are physical capture and hydroacoustic assessment techniques. The monitoring alternatives are listed in Table 3.3 and described in the text that follows.

Table 3.3. Monitoring Alternatives for Biological Data

\begin{tabular}{|c|c|c|c|}
\hline Component & Monitoring Method & Advantages & Disadvantages \\
\hline Mammals & Direct observation & Well-established & Labor-intensive \\
\hline Birds & Direct observation & Well-established & Labor-intensive \\
\hline \multirow{2}{*}{$\begin{array}{l}\text { Salmon } \\
\text { Adults }\end{array}$} & Physical capture - gill nets & Well-established & $\begin{array}{l}\text { Interfere with fisheries harvest, kill captured } \\
\text { fish }\end{array}$ \\
\hline & Hydroacoustics & $\begin{array}{l}\text { High sampling } \\
\text { intensity }\end{array}$ & No species identified \\
\hline \multirow[t]{2}{*}{$\begin{array}{l}\text { Salmon } \\
\text { juveniles }\end{array}$} & $\begin{array}{l}\text { Physical capture - various } \\
\text { nets and seines }\end{array}$ & Fish in hand & $\begin{array}{l}\text { Sampling could cause injuries } \\
\text { indistinguishable from blast effects; sampling } \\
\text { may be unrepresentative of population }\end{array}$ \\
\hline & $\begin{array}{l}\text { Exposure assessment: } \\
\text { hydroacoustics and caged } \\
\text { fish experiments }\end{array}$ & $\begin{array}{l}\text { Well-established, } \\
\text { high sampling } \\
\text { intensity }\end{array}$ & No species identified \\
\hline \multirow{2}{*}{$\begin{array}{l}\text { Eulachon } \\
\text { adults }\end{array}$} & Physical capture - nets & $\begin{array}{l}\text { Fish in hand; } \\
\text { existing surveys }\end{array}$ & Labor-intensive \\
\hline & Hydroacoustics & $\begin{array}{l}\text { High sampling } \\
\text { intensity }\end{array}$ & No species identified \\
\hline $\begin{array}{l}\text { Eulachon } \\
\text { eggs }\end{array}$ & $\begin{array}{l}\text { Physical capture - bongo net, } \\
\text { artificial substrate }\end{array}$ & $\begin{array}{l}\text { Fish in hand; } \\
\text { existing surveys }\end{array}$ & Population inferences difficult \\
\hline Sturgeon & Hydroacoustics & $\begin{array}{l}\text { High sampling } \\
\text { intensity }\end{array}$ & No species identified \\
\hline
\end{tabular}




\subsubsection{Physical Capture}

Physical capture of injured, moribund, and dead juvenile and adult salmonids, sturgeon, and adult eulachon following a blast event is likely problematic because of physical challenges of working with nets in a large river (e.g., tow, purse, gill) (Keevin et al. 2002). The difficulty is compounded because physical capture methods, particularly in a river environment, tend to cause physical injury and death to captured fish. The sampling method itself might injure or kill more fish than exposure to impulsive sound from blasting. In all cases, physical capture devices would have to be calibrated to determine their fish capture efficiency. Also, other investigators have experienced problems recovering fish injured during a blast or picking them from the water before they are taken by birds or sink (Munday et al. 1986). In some cases of blast monitoring, observations of bird activity and monitoring the species and sizes of fish recovered by birds following a blast have been the most successful elements of blast monitoring programs. In all cases where birds were actively feeding following a blast, recovery of moribund and dead fish has been limited.

Alternatives for direct capture include the following:

- Fixed-place fyke nets with live boxes or some variation might be possible, particularly for more nearshore locations. Fyke nets that would fish an adequate depth of the navigation channel would require large anchors to hold the net in place and would have other potential problems such as debris. Sampling volume would be small compared to total river cross section.

- Another type of fixed location fish capture devices, screw traps, might be feasible. However, these types of devices are typically limited to sampling surface layers or inshore locations. They are larger and would require robust anchoring to permit their use in the deeper, more rapid-moving navigation channel flow. Screw traps have the advantage of posing a low risk of injury to captured fish. Sampling volume would be small compared to total river cross section.

- Investigators working on the Fraser River in British Columbia had success catching juvenile salmon and adult eulachon with tow nets by towing downstream at a speed above that of the current (Stables et al. 2005). They did not report on fish condition and used the method only intermittently during their study. They had difficulty maintaining adequate tow speeds and controlling the tow net when towing into the current. Because of differences between the Columbia River at the project site and the Fraser River, the strategy of tow netting with flow is not a viable alternative for physical capture of fish.

- Purse seines and similar closing nets would have to be targeted on the moving mass of water comprising the impact area and have been found to be very difficult to set and recover in riverine settings. These types of nets require heavy equipment and extensive handling. In general, fish collected by purse seines have a high likelihood of being injured.

- Beach seines may be a viable physical capture alternative for near shore if care is taken during recovery. However, the sample volume would be limited, and areas without rock outcropping or riprap would be required.

- Near shore, it is possible that adult eulachon, both those in good health actively migrating and those taken by blasting, could be sampled preferentially with a beach seine. Following a blast, a seine could be set with one end anchored to shore and the upstream end left open to permit migrating eulachon within the cast of the net to move upstream out of the net, leaving only those more seriously 
injured or dead. Such strategies most likely would not be feasible in the deeper, more rapidly flowing water in the navigation channel.

- Gill and entanglement nets known to be effective for adult salmonids, sturgeon, and eulachon typically injure or kill captured fish and, for this reason, would not be acceptable for this project.

- Bongo nets and artificial substrates are commonly used to capture downstream moving eulachon eggs on the Columbia and other West Coast rivers to index spawning success (Romano et al. 2002a; McCarter and Hay 2003).

\subsubsection{Exposure-Response Assessment Techniques}

Because physical capture of fish, other than those recovered from the surface following a blast, is not without significant disadvantages, exposure-response assessment techniques for take estimation may be warranted. This monitoring alternative to take estimation would involve a three-step approach: unobtrusively surveying the impact area prior to blasting to estimate the abundance and distribution of fish of interest likely to be exposed to impulsive sound, estimating impulsive sound exposure these fish would experience, and estimating the probable take of fish by estimating the probability of mortal injury for exposed fish and integrating over the exposed population. The fish abundance and distribution survey tools would be fixed, and mobile single- and multi-beam hydroacoustics systems combined with acoustic video.

The exposure of fish to impulsive sound for each blast will be estimated by applying a sound attenuation model derived from impulsive signal observations made during each blast event to map the distribution of sound over the impact area. The response of juvenile fish to sound exposure will be expressed as the probability of mortality based on observations of the response of test fish (juvenile Chinook salmon and rainbow trout) from caged fish experiments to be conducted during the test blast and the first few days of the production blasting phases of the project. The response model for adult salmonids will be based on the findings of Yelverton (1975).

- Fixed and mobile hydroacoustic survey techniques for fish assessment are well established (Burczynski 1979; MacLennan and Simmonds 1992; Faber et al. 2005; Stables et al. 2005). A boat surveys for fish as it moves from station to station across the impact area. While on station for a prescribed amount of time, sampling occurs in the flowing water moving past the survey vessel. Thus the technique produces synoptic maps of fish density distributions for more stationary fish such as sturgeon in the impact area as well as the flux of fish, such as juvenile and adult salmonids and eulachon, through acoustically monitored volumes within, as well as immediately upstream and downstream of, the impact area. The disadvantage is lack of species identification except by direct capture ground truthing or, in some cases, by video or acoustic camera observations.

- Acoustic detection of moribund or dead fish would depend upon observation of differences in behavior between uninjured fish and seriously injured and dead fish. Acoustic video observations of fish at other locations in the river system have demonstrated the ability to clearly observe the movement patterns of actively swimming fish. A fish swimming into or with the current should be clearly distinguishable from one tumbling along the bottom or being passively carried with flow in an unnatural orientation. Acoustic video offers the advantage of not being affected by turbidity, does not require light, can distinguish inanimate objects from fish, and provides sufficiently clear images to estimate the size and activity level of fish. 
- Caged fish experiments to estimate the biological response of juvenile salmonids to the impulsive sound generated by a blast will provide better information than that currently available in the scientific literature if test fish are acclimated to a normal physical state, i.e., neutral buoyancy, prior to exposure. Such data would improve estimation of juvenile salmon take. However, extension of such experiments to eulachon or adult salmonids would likely prove too difficult, for many reasons, to be accommodated in this monitoring program.

\subsubsection{Monitoring Priorities}

In summary, the best assessment of take would be to recover all injured, moribund, and dead listed fish following each blast. The challenge is that the impact area is large (on the order of 35 acres in surface area), and physical capture of juvenile and adult fish in a large riverine environment in a manner sufficient to provide the sampling effort needed for precise estimates of take, particularly given the small levels of take expected (Table 2.1), is difficult. This would require use of various types of nets and other implements that might well injure more listed fish than would exposure to the impulsive sound generated by blasts. Therefore, although physical capture was considered during monitoring plan design, physical capture will not be used to estimate take of fishes. Thus, based on the problem assessment in view of species vulnerabilities and monitoring alternatives, the priorities for monitoring are shown in Table 3.4.

Table 3.4. Priorities for Biological Monitoring - Approximate Monitoring Periods and Methods

\begin{tabular}{|c|c|c|}
\hline Component & Monitoring Period & Monitoring Method \\
\hline Mammals & Entire 4 months ${ }^{(\mathrm{a})}$ & Direct observation \\
\hline Birds & Entire 4 months ${ }^{(a)}$ & Direct observation \\
\hline Salmon adults & November-December $^{(a)}$ & Hydroacoustics \\
\hline Salmon juveniles & January-February $^{(\mathrm{a})}$ & Hydroacoustics \\
\hline Eulachon adults & January, February $^{(a)}$ & $\begin{array}{l}\text { Hydroacoustics } \\
\text { Physical capture }\end{array}$ \\
\hline Eulachon eggs & February $^{(a)}$ & Artificial substrate \\
\hline Sturgeon & Entire 4 months & Hydroacoustics \\
\hline
\end{tabular}

(a) Or until blast operations cease.

The transition from monitoring for adults to juveniles will be based on observations of downstream migration of juvenile chum salmon and forecasting using an acquired thermal unit approach. 


\subsection{Methods}

This section contains descriptions of the general approach and methods for physical and biological data collection and statistical analysis for the monitoring priorities identified in the problem assessment (Table 3.4).

\subsection{General Approach}

The blasting project is divided into an initial test blast phase, in which alternatives for the number and configuration of charges for production blasting will be evaluated, and a second phase of production blasting. Both phases are scheduled to occur between November 1, 2009, and February 28, 2010.

Significant differences in sound exposure may occur over the range of blast configuration alternatives to be evaluated during phase I of the project. For example, the number of impulses and duration of sound exposure for the 16-charge test blast 1 (Section 5.2.1 of the blasting plan) will be approximately 16 sequential impulses within $117 \mu$ s while that for the 96 charges in test blast 4 (Section 5.2.4 of the blasting plan) will be 96 sequential impulses within approximately $702 \mu \mathrm{s}$. With the exception of studies conducted to evaluate the effects of multiple impulsive sound exposures for seismic air guns and pile driving, biological response data are not available for the response of juvenile and adult salmonids, eulachon, fish eggs, and sturgeon to exposure to multiple impulses from blasting events. Because of differences in the characteristics of sound impulses between explosive and non-explosive sources, the information for air gun and pile driving impulsive sound exposure are of limited utility to assess the likely consequences of exposure to the complex impulsive sounds to be generated by the multiple-charge blast events that will occur during this project. Therefore, caged fish (juvenile hatchery Chinook salmon and juvenile rainbow trout) will be used to develop biological response data to augment information available in the literature to aid evaluation of production blast configuration alternatives. Monitoring of take also will be conducted during the test blast phase of the project. The approach to monitoring will be the same as that described in subsequent sections for the production blasting phase of the project.

Because the risk of barotrauma for fish exposed to underwater blasting are uncertain, the general approach to monitoring to estimate take will be conservative and will entail development of exposure and biological response models. The management of risk must balance the cost of detecting rare exposures having high risk of injury with the cost of monitoring across a much broader range of exposures having lower risk of injury. Models for exposure of biota to blasting are available for some biota, but not juvenile and adult salmon, the focal species in this work because of its ESA-listed status. Coupling in situ cage studies of dose-response with field monitoring of fish distribution and sound overpressure levels will allow estimation of the population response on a per-blast basis. For marine mammals and diving birds, observational census surveys will be conducted.

The general approach advocated in this monitoring plan is to

1. Observe the total overpressure signal generated by each blast event.

2. Survey for the presence of marine mammals and diving birds in an area that extends radially 2,000 ft from the blast event location. If marine mammals and diving birds are detected within the survey area, inform the responsible parties of their presence prior to blasting. 
3. Use fixed location and mobile hydroacoustic techniques to estimate the location and number of fish of interest in the impact area at the time of blast.

4. Develop response data for juvenile salmonids by performing a set of controlled exposure studies (experiments with caged juvenile salmonids) during blast testing and at the initiation of production blasting. For adult salmonids, apply the response data presented by Yelverton (1975).

5. Survey the impact area as soon as possible following blast events to recover any moribund or dead fish available at the water surface. Perform necropsies on recovered fish to determine cause of death.

6. Estimate take for each blast event.

\subsection{Physical Data}

Physical data will include monitoring blast impulse signals and water velocities. Equipment, deployment techniques, monitoring locations, and monitoring frequencies are described below.

\subsubsection{Blast Impulse Signals}

The project blasting plan ${ }^{1}$ developed for USACE review provides for a period prior to production blasting to test alternatives for explosive charge arrays and other elements of configuration such as number of charges, spacing between charges, and depth of burden over charges. The range of alternatives include a 16-charge linear array with delays between charges that will result in a sound exposure of approximately $117 \mu$ s duration to 96 charges in a 6 by 16 matrix that would result in a sound exposure duration of approximately $700 \mu \mathrm{s}$. The criterion for sound production given in the project blasting plan (Section 4.2.3(b), Revision 1.3, p. 4.5) is $70 \mathrm{psi}$ at $140 \mathrm{ft}$ from the blasting area. This criterion appears to be based on testing conducted by the USACE in preparation for in-rock underwater blasting conducted in Wilmington harbor (Rickman 2000).

Precise a priori estimation of peak overpressures and impulse for explosions from buried underwater charges is complicated by many factors, particularly in shallow water environments; it is useful for only general project planning tasks. Reliance on peak and impulse measures for biological assessment purposes is further complicated by the fact that although the total sound exposure is a sequence of individual explosions, the time between explosions is small and the exposure is more like a single continuous event. Therefore, monitoring for take assessment should focus on sound exposure level (SEL) that is log transformed acoustic flux density without scaling for acoustic impedance. Sound exposure level should be measured over the total duration of exposure. It is not clear at this time whether or not impulse should be limited to that received from the first charge in a blast event or some other observation that includes all the impulses in the blast event. Energy flux density, and thereby SEL, and impulse have been shown to correlate better with fish injury than peak overpressure (Munday et al. 1986). The ratio of peak negative overpressure and static pressure at acclimation depths has been used as a variable to predict

${ }^{1}$ Columbia River Channel Improvement Project - Operational Blasting Plan, submitted to the U.S. Army Corps of Engineers, Portland District, in 2009 by Contract Drilling \& Blasting LLC, S.P. Case, and Aimone-Martin Associates, LLC. 
the probability of mortal injury for juvenile Chinook salmon exposed to rapid decompression. ${ }^{2}$ Sound exposure level frequently is used instead of energy flux density to describe sound exposure. In cases where plane wave conditions cannot be ensured, scaling by acoustic impedance as required for estimation of energy flux density is not appropriate. Such is the case for the sound field generated by acoustic blasts in shallow riverine environments. In these cases, SEL, a dimensionless index for energy flux density, is a more appropriate metric to characterize sound exposure.

It cannot be assumed that the distribution of sound will be symmetrical around a blast center, particularly in a riverine environment with significant differences in bathymetry longitudinally and orthogonally to the river thalweg. In addition, for charges buried in bedrock underwater, it has been shown that the resulting in-water waveform is considerably different from that of a charge exploded in water. Although peak overpressures are reduced significantly to somewhere between 6\% (Nedwell and Thandavamoorthy 1992) and 14\% (Rickman 2000), the duration of the primary impulse is much longer and the shape is dependent upon the ratio of primary contribution of the energy from the rock-borne shock wave and secondary contribution from gases that may escape into the water column (Nedwell and Thandavamoorthy 1992). The result can be much higher sound levels, particularly at longer ranges from the explosion location, than expected by gas bubble mechanics alone. Seismic propagation of energy has other effects on characteristics of the sound to which fish may be exposed (Munday et al. 1986). The characteristics of sound generated by the rock-borne shock wave are likely to be much less impulsive, thereby reducing the risk of percussive injury. Injury by rapid decompression would remain as the primary threat to animal health from this source of sound. An added complication for this project is that no information is available in the biological literature to anticipate the characteristics of impulsive sound exposure and biological response from the multiple-charge blasting strategies to be used for this project. Although data exist for exposure of fish to the sound from a single in-water explosion (Yelverton et.al. 1975), there are no similar stimulus-response data for multiple impulse exposures from an array of buried charges.

Exposure monitoring for take assessment will require observation or estimation of blast exposure characteristics in locations where animals are either observed or expected to occur, to ensure that the conditions of exposure are adequately and accurately observed. The blasting contractor intends to deploy blast sensors and record the overpressure produced by blasting events. These sensors, which consist of transducers linked to shore- or boat-based acquisition hardware by cable, will be placed at fixed locations to meet the data needs of the blasting contractor to assess alternatives during the test blast period and to monitor each blast event during production blasting. Additional deployment locations may be necessary to provide adequate data to estimate fish exposure over the blast impact area. Acquired underwater sound data should be processed to estimate positive and negative peak overpressures, impulse, SEL, and other signal characteristics per charge within blasting events that may be helpful in evaluation of exposure of fish to impulsive sound.

\subsubsection{Water Velocity}

A standard acoustic Doppler current profiler will be deployed to obtain estimates of water velocity. The instrument will need to be located at a range so that it will not be exposed to high-energy impulsive

\footnotetext{
${ }^{2}$ Carlson TJ, RS Brown, JR Skalski, and RL Townsend. Response of Juvenile Chinook Salmon to Rapid Decompression. Unpublished draft report to the U.S. Army Corps of Engineers, Portland District, in preparation by Pacific Northwest National Laboratory, Richland, Washington.
} 
signals during blasting or removed from the river during blasting. During pre-blasting hydroacoustic surveys, it will be deployed on a mobile survey vessel.

\subsubsection{Summary and Sampling Design}

For physical data, the monitoring equipment and deployment techniques are summarized in Table 4.1. The sampling design, including monitoring locations and frequencies, is summarized in Table 4.2. The sampling design may be modified after results from initial blast monitoring are available.

Table 4.1. Monitoring Equipment and Deployment Techniques for Physical Data

\begin{tabular}{llc}
\hline \multicolumn{1}{c}{ Component } & \multicolumn{1}{c}{ Monitoring Equipment } & Deployment Technique \\
\hline Blast impulse signal & Blasting contractor cabled blast sensor array. & Fixed stations \\
Water velocity & $\begin{array}{l}\text { Acoustic Doppler current profiler: water velocity } \\
\text { direction and speed }\end{array}$ & Fixed station \\
\hline
\end{tabular}

Table 4.2. Sampling Design - Monitoring Locations and Frequencies for Physical Data

\begin{tabular}{lll}
\hline \multicolumn{1}{c}{ Component } & \multicolumn{1}{c}{ Monitoring Location } & Monitoring Frequency \\
\hline Blast impulse signal & $\begin{array}{l}\text { Need data to estimate impulsive sound at several } \\
\text { locations within the blast impact area. }\end{array}$ & $\begin{array}{l}\text { Each blast event } \\
\text { Water velocity }\end{array}$ \\
\hline
\end{tabular}

\subsection{Biological Data}

Biological data will need to be collected on marine mammals, diving birds, adult and juvenile salmonids, and eulachon adults and eggs. A summary of equipment, deployment, locations, and frequencies for monitoring is provided at the end of this section.

\subsubsection{Marine Mammals}

It is assumed that any and all marine mammals entering the impact area would be of concern. Prior to blasting, surveys will be conducted simultaneously both upstream and downstream of the blast location to search for marine mammals. The surveys will be scheduled approximately 1 hour prior to blasting to provide response time if needed following report to the USACE of their presence within 2,000 ft of a blast event location. The species and other relevant information about any marine mammals encountered during a survey will be noted.

As defined by NMFS (correspondence from R. Anderson to K. Larson, October 1, 2009),

A marine mammal safety zone of 2,000 feet shall be established to protect marine mammals. Blasting will not occur while marine mammals are within the established safety zone. If a marine mammal is seen above water, then dives below, blasting will be delayed for 15 minutes following each dive. If, after the 
15 minute period no marine mammals are observed in the safety zone, it will be assumed that the animal has moved beyond the safety zone, and blasting may move forward. This 15-minute criterion is based on evidence that harbor seals in San Francisco Bay dive for a mean time of 0.50 minutes to 3.33 minutes (Harvey and Torok 1994), and that California sea lions in Puget Sound, Washington dive for a mean time of 1.4-1.8 minutes (Loughlin et al. 2003). NMFS assumes dive times in Columbia River are similar to those in other systems.

If a dead, injured, or sick endangered or threatened species specimen is located during Project dredging, disposal, monitoring, research, or restoration activities, initial notification must be made to the National Marine Fisheries Service Law Enforcement Office, at the Vancouver Field Office, 600 Maritime, Suite 130, Vancouver, Washington 98661; phone: 360/418-4246.

Care should be taken in handling sick or injured specimens to ensure effective treatment and care or the handling of dead specimens to preserve biological material in the best possible state for later analysis of cause of death. In conjunction with the care of sick or injured endangered and threatened species or preservation of biological materials from a dead animal, the finder has the responsibility to carry out instructions provided by Law Enforcement to ensure that evidence intrinsic to the specimen is not disturbed.

\subsubsection{Birds}

Within one hour of blasting, the impact area will be surveyed for diving birds. Any diving birds resting on the water surface will be hazed to move them out of the impact area. Monitoring for diving birds will continue through the blast event with hazing as necessary to prevent the birds from either diving or landing in the impact area. The species and other relevant information about any protected birds encountered during a survey will be noted. As an element of take assessment, observers will monitor bird activity and attempt to identify fish recovered by birds from the blast site.

\subsubsection{Adult and Juvenile Salmonids}

\subsubsection{Hydroacoustic Surveys}

Data will be collected using mobile and fixed-location hydroacoustic survey methods to estimate the overall abundance and distribution of fish in the impact area at the time of a blast event. Sampling will be conducted from a number of boats equipped with active hydroacoustic systems (split-beam and acoustic video). Split-beam hydroacoustic systems can measure relative differences in the target strength of ultrasonic echoes and, thus, the size of the fish located within the ensonified beam. Split beams are also capable of measuring movement direction through the acoustic beam by detecting the difference in phase shift (translated to angle and position) of the returning echo from each of the "splits," which are formed by grouping subsets of an array of ceramic elements that comprise a split-beam transducer. 
Underwater acoustic imaging devices ${ }^{3}$ will be deployed concurrently with the split-beam hydroacoustic devices. Acoustic cameras can produce video-like sequences of images with nearphotographic clarity of individual objects because the field of view is composed of multiple narrow beams. Even in turbid water, the instruments produce a near-field (within $20 \mathrm{~m}$ ) image resembling that of a video camera. To be clear, the high resolution is only in the two dimensions of the plane in which the instrument is aimed. Unlike single- and split-beam hydroacoustic transducers, however, an acoustic camera can be aimed obliquely to a flat surface and still record fish swimming very near that surface. An acoustic camera will be a useful assessment tool because it is highly portable, requires minimal site preparation to deploy repeatedly, and produces sequences of images that are easy to process to estimate fish abundance.

Mobile survey data acquisition, processing, and analysis will follow the guidelines of Burczynski (1979) modified as necessary to accommodate the direct target strength measurement capability of splitbeam devices and expected predominance of single fish. Acoustic imaging will be used in both mobile and fixed location assessment modes. In the mobile mode, acoustic imaging will be used to provide additional information to aid identification of the species of special targets of interest such as those suspected to be sturgeon. The methods of Skalski et al. (1993) and Johnson et al. (1994) will be used to determine the spatial and temporal coverage required to adequately sample the impact region and to process and analyze acquired data. Because of the large uncertainty about the abundance of fish during the project, pilot data from initial surveys will be necessary to complete the design of fixed-location and mobile hydroacoustic surveys.

\subsubsection{Caged-Fish Experiments}

Caged fish will be used during both the test blast and production blasting portions of the project. In both cases, test fish will be juvenile Chinook salmon and juvenile rainbow trout. During these cage tests, a critical factor will be acclimation of test fish prior to exposure to ensure a more normal physiological state at exposure. Studies conducted by Carlson and Abernethy (2005) have shown that physostomous salmonids respond to rapid decompression very differently whether they have or have not achieved neutral buoyancy prior to exposure. Salmonids that do not have air in their swim bladders at exposure respond similarly to rapid decompression as fish without swim bladders. It is expected that the same will be true for both percussive and decompressive exposures. Preparing salmonids for these types of exposure requires special techniques. During handling, salmonids typically burp the air from their swim bladders and are not in a normal physiological state (air in the swim bladder) when placed in cages. Typically, cages are immediately submerged to test depths. When this occurs, salmonids that must gulp air at the surface to fill their swim bladders do not have access to air and remain negatively buoyant for the test and then respond to both percussion and decompression like fish without swim bladders. This results in erroneous information about their response to percussive and decompressive forces. Methods have been developed to permit salmonids in pressure chambers to achieve neutral buoyancy (Carlson and Abernethy 2005) but, to our knowledge, have not been developed for caged salmonids in natural settings. Caged fish experiments that are conducted during both phases of this blasting project will be conducted to ensure that the test fish are in an appropriate physiological state prior to exposure.

Caged fish observations will be obtained for each test blast alternative evaluated during the test blast phase of the project. At least two cages, each containing at least 100 juvenile Chinook salmon and

\footnotetext{
${ }^{3}$ See http://www.soundmetrics.com/ or http://www.blueview.com/.
} 
juvenile rainbow trout with body mass less than $25 \mathrm{~g}$, will be deployed for each test. One cage of each species will be deployed as near as possible to the blast sensor to be deployed by the blasting contractor at a range of $140 \mathrm{ft}$ from the blasting location. Another cage of each species will be deployed at a range of approximately $300 \mathrm{ft}$ from the blasting location, again as near as possible to a blast sensor to be deployed by the blasting contractor. Cages will be located at a depth of approximately $6 \mathrm{ft}$. This depth is within the preferred depth range of out-migrating juvenile salmonids. After exposure, all dead test fish will be necropsied. All live fish will be held for $48 \mathrm{hr}$ to assess delayed mortality. During the holding period, any fish that die will be necropsied. At the end of the 48-hr holding period, all remaining fish will be euthanized and necropsied. Sound exposure level and other sound exposure metrics will be estimated for each cage of fish. The sound exposure metrics and the proportion of fish that died will be tabulated for each cage of fish for each test blast through the test blast phase.

Cage experiments to determine the dose-response curve for juvenile salmonids to blasting will be conducted during the initial phase of production blasting. The location of cages will be determined using overpressure data acquired by the blasting contractor. Cage locations, range from the blast location, and depth will be selected to permit acquisition of biological response data over a range of SEL exposures that correspond to a range of expected biological response (probability of mortal injury) between 0.05 and 0.9 probability of mortal injury. Hatchery juvenile Chinook salmon and rainbow trout will be placed in the cages and permitted to depth-acclimate prior to exposure to the impulsive sound from a blast. The cages will be designed to provide a refuge to the caged fish from flow of water through the cages and to permit the fish to acclimate (become neutrally buoyant) at the deployment depth. Generalized linear models ${ }^{4}$ will be used to identify parameters for a binomial likelihood that will best describe the response (probability of mortal injury) of juvenile Chinook salmon and rainbow trout to production blasts (i.e., SEL). The location of cages as well as the number of fish per cage will be continuously assessed during derivation of the dose-response for juvenile Chinook and rainbow trout to ensure adequate sampling of the sample space defined by SEL and probability of mortality. It is expected that a minimum of 10 days of successful sampling with two test periods (two blast events) per day and a minimum of two cages of fish of each species per test, each containing a minimum of 20 fish, will be needed to adequately cover the mortal injury-SEL sample space. Additional sampling days may be required to fill holes in sample space coverage, and larger numbers of test fish also may be needed, depending upon the response of test fish to sound exposure. The conduct of this portion of monitoring will need to be highly adaptive to observations of both the characteristics of sound exposure and the response of test animals.

\subsubsection{Exposure Modeling - Integration}

The exposure model provides an integration of available data such as sound field measurements, hydrodynamic conditions, and animal behavior and distribution. The intent is to obtain increasingly realistic and validated estimates of the exposure of priority species to stressor fields, in this case juvenile salmonids, to the effects of underwater blasting. The exposure of the population of animals transiting the impact area is best estimated by integrating the expected sound field, hydrodynamics, and fish behavior (distribution and movement patterns) over the extent of the stressor field generated by blasting. The result will be the distribution of stressor "dose" experienced by the population. These dose estimates will

\footnotetext{
${ }^{4}$ Carlson TJ, RS Brown, JR Skalski, and RL Townsend. Response of Juvenile Chinook Salmon to Rapid Decompression. Unpublished draft report to the U.S. Army Corps of Engineers, Portland District, in preparation by Pacific Northwest National Laboratory, Richland, Washington.
} 
then be used to estimate the response of the population to the stressor, given information from the hydroacoustic surveys and caged fish experiments.

\subsubsection{Eulachon Adults and Eggs}

Assessment of the abundance of eulachon adults and eggs will not be initiated until their presence in the impact area is confirmed by state fish management agencies. Abundance assessment of adult eulachon within the blast impact area will be determined using acoustic video. Artificial substrate as described by Romano et al. (2002a) will be used to sample eulachon eggs if necessary. Captured eggs will be examined to detect the presence of eggs damaged by impulsive sound. Such examination might require holding eggs for a period of a couple of days in order to use development as one measure of the viability of captured eggs.

\subsubsection{Sturgeon}

Juvenile and adult sturgeon will be sampled using hydroacoustic techniques. The method will be similar to that described above for juvenile salmon, with emphasis placed on mobile survey methods using acoustic video cameras. Presence of sturgeon in the impact area, detected during the pre-blast survey, will be reported to responsible parties.

\subsubsection{Summary and Sampling Design}

For biological data, the monitoring equipment and deployment techniques are summarized in Table 4.3. The sampling design, including monitoring locations and frequencies, is summarized in Table 4.4.

Table 4.3. Monitoring Equipment and Deployment Techniques for Biological Data

\begin{tabular}{|c|c|c|}
\hline Component & Monitoring Equipment & Deployment Technique \\
\hline Marine mammals and birds & $\begin{array}{l}\text { Video cameras (digital video recording for archive), } \\
\text { visual observations from boats }\end{array}$ & Boat surveys \\
\hline $\begin{array}{l}\text { Salmon adults and } \\
\text { juveniles; sturgeon }\end{array}$ & $\begin{array}{l}\text { Acoustics (split-beam, acoustic imaging) and caged } \\
\text { fish experiments }\end{array}$ & $\begin{array}{l}\text { Mobile and fixed surveys } \\
\text { from boats }\end{array}$ \\
\hline Eulachon adults & Acoustic video & Boat surveys \\
\hline Eulachon eggs & Artificial substrate & Boat surveys \\
\hline
\end{tabular}


Table 4.4. Sampling Design - Monitoring Locations and Frequencies for Biological Data

\begin{tabular}{lll}
\hline \multicolumn{1}{c}{ Component } & \multicolumn{1}{c}{ Monitoring Location } & \multicolumn{1}{c}{ Monitoring Frequency } \\
\hline Mammals and birds & $\begin{array}{l}\text { Within 2,000 ft upstream and } \\
\text { downstream of blast location }\end{array}$ & $\begin{array}{l}\text { Before: } 1 \mathrm{hr} \text { prior to blast } \\
\text { After: } 30 \mathrm{~min} \text { after blast }\end{array}$ \\
$\begin{array}{l}\text { Listed fish, salmon adults and } \\
\text { juveniles; sturgeon }\end{array}$ & $\begin{array}{l}\text { Within 2,000 ft upstream and } \\
\text { downstream of blast location } \\
\text { Mobile and fixed-location } \\
\text { hydroacoustics. }\end{array}$ & $\begin{array}{l}\text { Before: } 2 \mathrm{hr} \text { prior to blast } \\
\text { After: } 30 \mathrm{~min} \text { after blast }\end{array}$ \\
Same as for salmonids and sturgeon & $\begin{array}{l}\text { Before: } 1 \mathrm{hr} \text { prior to blast } \\
\text { After: } 30 \mathrm{~min} \text { continuous } \\
\text { monitoring following blast }\end{array}$ \\
\hline Eulachon eggs & Same as for salmonids and sturgeon & $\begin{array}{l}\text { Before: } 1 \text { hr prior to blast } \\
\text { After: } 30 \mathrm{~min} \text { continuous } \\
\text { monitoring following blast }\end{array}$ \\
\hline
\end{tabular}

\subsection{Estimation of Take}

Fixed-location and mobile hydroacoustic surveys prior to each blast event will provide data needed to estimate the number and distribution of fish in the potential impact area defined by the 10-psi peak pressure minimum effect threshold specified in the project Biological Opinion. It is estimated that this area will extend about $700 \mathrm{ft}$ from the center of the charges that comprise a blast event. The actual extent and shape of the impact area are likely to differ between blast events, and it will be smaller for adult salmonids than for juvenile salmonids. In some cases, for high-value fish such as adult sturgeon, acoustic imaging will be used to obtain additional information to improve efforts to estimate the species of detected fish. In all other cases, detected fish will be considered to be salmonids, and their size category (juvenile or adult) will be estimated from data acquired using split-beam hydroacoustics or acoustic imaging. The exception to this will be adult eulachon if they occur in the project area during blasting. When eulachon occur, they will be identified and their abundance and distribution estimated. In cases where additional species identification effort is warranted, acoustic imaging will be used to obtain information to improve species identification.

The hydroacoustic surveys cannot provide an unambiguous estimate of the number and distribution of fish exposed at the instant a blast occurs. The best that can be provided is an estimate of the likely number and distribution of fish in the impact area during each blast event. The project area is very dynamic, the river is flowing past the project site, the fish of interest are mobile and, with the possible exception of sturgeon, transiting the project area, and the survey effort will take a finite amount of time.

To estimate the location and abundance of semi-resident fish such as sturgeon in the impact area, mobile hydroacoustic surveys will be conducted. The number of transects will be the number that can be conducted during a 2-hr period preceding a blasting event.

The location and abundance of transient fish, such as juvenile and adult salmonids and eulachon, in the impact area at the time of a blast event will be estimated using fixed-location hydroacoustic methods. Active hydroacoustic systems, a mixture of split-beam and acoustic video, will be deployed from boats anchored as close to the blast event location as permissible. The acoustic screen will be deployed 
upstream of the blast location during monitoring for juvenile fish and downstream of the blast location during monitoring for adult fish. The systems will be deployed so that the most intense sampling effort is allocated to the river cross section where the highest sound energy is expected. The spatial and temporal data for fish passing through the fixed location acoustic screens will be used to estimate the probable number and location of fish within the impact area at the time of a blast event.

A generalized model for attenuation in sound with increase in radial distance from the center of a blast will be derived at conclusion of the test blast phase of the project in collaboration with the blasting contractor. The parameters of the model will be scaled for each blast event using observations of the sound generated by the blast event made by the blasting contractor. This element of take estimation will be treated as deterministic unless the blast monitoring conducted by the blasting contractor has sufficient redundancy at ranges from the center of blasting events to permit estimation in the variability in sound exposure as a function of radial distance.

For juvenile salmonids, their biological response to sound exposure will be available in the form of a likelihood model that relates probability of mortality to one or more sound exposure metrics. This model will be the result of the caged fish experiments conducted during the test blast phase and at the beginning of production blasting. The take of juvenile salmonids will be estimated by computing the weighted sum of the radial distribution of juvenile salmonids estimated from hydroacoustic data. The weighting will be the probability of mortal injury by range obtained by mapping probability of mortal injury to range using the sound exposure and biological response models. Error will be propagated through the analysis model to permit estimation of confidence limits for take. More information about the take estimation method is included as an Appendix.

The exposure of adult salmonids will be estimated using the sound attenuation model described previously, with impulse as the exposure metric. The relationship provided by Yelverton (1975) will be used to estimate the probability of mortality given exposure as impulse. The same take estimation approach will be used for adult fish as for juvenile fish. 


\subsection{Data, Reporting, and Adaptive Management}

This section presents the plan for data, reporting, and adaptive management. A single entity should be responsible for these elements of the monitoring plan.

\subsection{Data}

This section on monitoring data addresses the response variables, data management, quality assurance, and communications.

\subsubsection{Response Variables}

The primary response variables will the number of animals observed dead or moribund following a blast event and the take estimated from acoustic observations and exposure response data developed during monitoring and available from the literature (Table 5.1).

Table 5.1. Template for a Summary Data Table

\begin{tabular}{lc}
\hline Category & Value \\
\hline Number of Marine Mammals Observed in the Safety Zone at Blast Time & 0 \\
\hline Number of Sturgeon Observed during Pre-Blast Surveys & 0 \\
\hline $\begin{array}{l}\text { Number of Mortalities Observed after the Blast (by category): } \\
\text { marine mammals; adult salmon; sturgeon; eulachon }\end{array}$ & 0 \\
\hline Estimated Take of Listed Salmon & 0 \\
\hline Cumulative Estimated Take of Listed Salmon & 0 \\
\hline
\end{tabular}

\subsubsection{Management}

Data management will entail 1) forming a data management system; 2) finalizing what data will be collected, by whom, how often, where, and when; 3) defining data standards; 4) defining metadata needs; 5) establishing access methods and policies; 6) establishing how the data will be used and by whom; and 7) designating staff to implement the data standards and maintain the database. The data management effort will feed directly into data dissemination. 


\subsubsection{Quality Assurance}

Monitoring activities must be covered by a quality management system of some kind. Such systems are typically designed to ensure that results are scientifically valid, unbiased, and free from real or perceived conflict of interest. A quality management system is usually composed of a hierarchy of policies and procedures that integrate quality-related aspects of various management system products, processes, and tools designed to meet the quality needs of research activities while maintaining program objectives. Researchers will perform their research activities in accordance with the quality assurance requirements stated in the quality management system.

\subsection{Communications and Reporting}

Unambiguous channels of communication among the researchers, regulatory agencies, and the USACE will be critical to the monitoring program's success. The monitoring project manager will convene weekly crew meetings, write and share meeting notes, and post pertinent project documents and information on an Internet share site, among other communication mechanisms. They will provide progress reports to the USACE describing accomplishments, plans, and issues. They will communicate with researchers, regulators, and interested parties as appropriate and determined by the USACE.

Reports on visual observations of marine mammals, diving birds, and adult sturgeon in the impact region will be provided after each blast event. As well, estimation of take and any relevant supporting material will be provided the day after each blast event.

The environmental monitoring contractor will report directly to the single point of contact for the USACE (Figure 5.1). The USACE will have responsibility to communicate results to the blasting contractor and the regulatory agencies. To provide understanding of planned activities and environmental concerns, the environmental monitoring contractor may communicate directly with the blasting contractor and the regulatory agencies, as necessary and with the knowledge of the USACE.

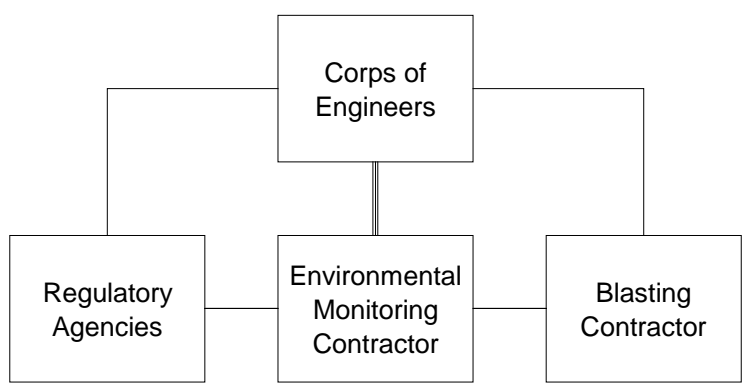

Figure 5.1. Communications Diagram

For example, the blasting permit will require the contractor to inform the National Marine Fisheries Service if marine mammals are present in the impact area so that any necessary measures to protect the animals can be taken. The chain of communication would be monitoring contractor to USACE to blasting contractor to regulatory agency. Single points of contact within each organization and contact information will be established before blasting commences. 


\subsection{Adaptive Management}

The monitoring plan will be implemented to accommodate an adaptive management framework (Figure 5.2). Adaptive management is a structured learning process for testing hypotheses through management experiments in natural systems, collecting and interpreting new information, and making changes based on monitoring information to improve the management of ecosystems. The USACE has established an Adaptive Management Team for the blasting work. The monitoring and blasting contractors and regulatory agencies, along with the USACE, will be represented on the Adaptive Management Team.

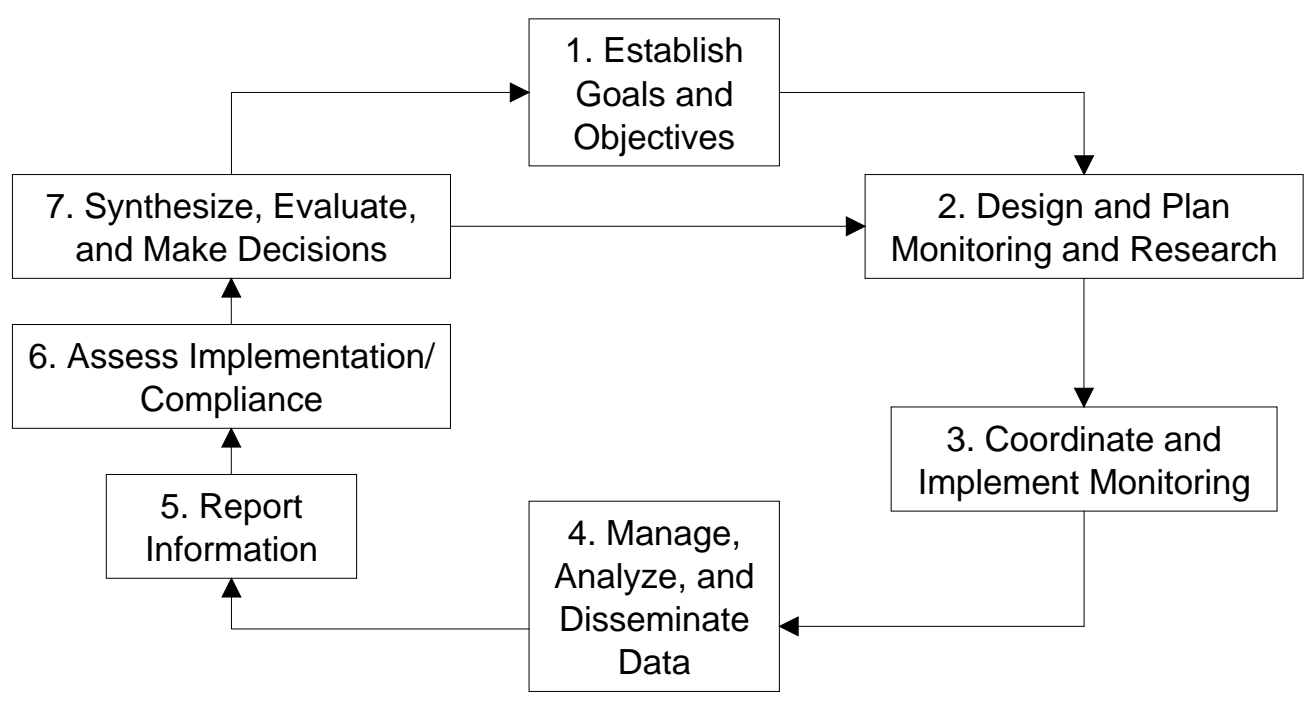

Figure 5.2. An Adaptive Management Process for Blasting 


\subsection{References}

Burczynski JJ. 1979. Introduction to the use of sonar systems for estimating fish biomass.

FAO-FIRM--T191, Food and Agriculture Organization of the United Nations, Rome.

Carlson TJ and CS Abernethy. 2005. Pilot Study of the Effects of Simulated Turbine Passage Pressure on Juvenile Chinook Salmon Acclimated with Access to Air at Absolute Pressures Greater than Atmospheric. PNNL-15011, Pacific Northwest National Laboratory, Richland, Washington.

Faber DM, ME Hanks, SA Zimmerman, JR Skalski, and PW Dillingham. 2005. The Distribution and Flux of Fish in the Forebay of The Dalles Dam in 2003. PNNL-14628, Pacific Northwest National Laboratory, Richland, Washington.

Friesen TA, JS Vile, and AL Pribyl. 2007. Outmigration of juvenile Chinook salmon in the lower Willamette River, Oregon. Northwest Science 18(3):173-190.

Geist DR and AJ Currie. 2006. Evaluation of Salmon Spawning below the Four Lowermost Columbia River Dams. DOE/BP-00000652-32, Bonneville Power Administration, Portland, Oregon.

Goertner JF, WL Wiley, GA Young, and WW McDonald. 1994. Effects of Underwater Explosions on Fish Without Swim Bladders. Report No. A704672, Naval Surface Warfare Center, Dahlgren Division, White Oak Detachment, Silver Spring, Maryland.

Harvey JT and ML Torok. 1994. Movements, Dive Behaviors, and Food Habits of Harbor Seals (Phoca vitulina richardsi) in San Francisco Bay, California. Moss Landing Marine Laboratories, Moss Landing, California.

Howell MD, MD Romano, and TA Rien. 2001. Outmigration Timing and Distribution of Larval Eulachon, Thaleichthys pacificus, in the Lower Columbia River, Spring 2001. Washington Department of Fish and Wildlife, Vancouver, Washington.

Johnson GE, JR Skalski, and DJ Degan. 1994. Statistical precision of hydroacoustic sampling of fish entrainment at hydroelectric facilities. North American Journal of Fisheries Management 14:323-333.

Johnson J, J Poirier, and T Whitesel. 2008. Evaluate Factors Limiting Columbia River Gorge Chum Salmon Populations. Document ID \#P105246, Bonneville Power Administration, Portland, Oregon.

Keevin TM and GL Hempen. 1997. The Environmental Effects of Underwater Explosions with Methods to Mitigate Impacts. U.S. Army Corps of Engineers, St. Louis District, St. Louis, Missouri.

Keevin TM, GL Hempen, RD Davinroy, RJ Rapp, MD Petersen, and DP Herzog. 2002. The use of high explosive to conduct a fisheries survey at a bendway weir field on the middle Mississippi River.

International Society of Explosive Engineers 1:382-393.

Keller K. 2007. 2006 Columbia River Chum Salmon Return. Document ID \#P103825, Bonneville Power Administration, Portland, Oregon. 
Loughlin TR, JT Sterling, RL Merrick, JL Sease, and AE York. 2003. Diving behavior of immature Steller sea lions (Eumetopias jubatus). Fishery Bulletin 101(3):566-582.

McCarter PB and DE Hay. 2003. Eulachon Embryonic Egg and Larval Outdrift Sampling Manual for Ocean and River Surveys. Canadian Technical Report of Fisheries and Aquatic Sciences 2451, Fisheries and Oceans Canada, Science Branch, Pacific Region, Pacific Biological Station, Nanaimo, British Columbia.

MacLennan DN and EJ Simmonds. 1992. Fisheries Acoustics. Chapman \& Hill, New York.

Munday DR, GL Ennis, DG Wright, DC Jeffrues, ER McGreer, and JS Mathers. 1986. Development and Evaluation of a Model to Predict Effects of Buried Underwater Blasting Charges on Fish Populations in Shallow Water Areas. Canadian Technical Report of Fisheries and Aquatic Sciences No. 1418, Department of Fisheries and Oceans, Habitat Management Division, Water Use Unit, Vancouver, British Columbia.

Nedwell JR and TS Thandavamoorthy. 1992. The waterborne pressure wave from buried explosive charges: and experimental investigation. Applied Acoustics 37(1):1-14.

NMFS. 2002. Columbia River Federal Navigation Channel Improvements Project Biological Opinion. National Marine Fisheries Service, Northwest Region, Portland, Oregon.

NMFS. 2008. Summary of Scientific Conclusions of the Review of the Status of Eulachon (Thaleichthys pacificus) in Washington, Oregon, and California. Northwest Fisheries Service Center, National Marine Fisheries Service, Seattle, Washington.

NOAA. 2008. Seal and sea lion facts of the Columbia River and adjacent nearshore marine areas. National Oceanic and Atmospheric Administration, Northwest Regional Office, Seattle, Washington. Available at www.nwr.noaa.gov/Marine-Mammals/ (December 2009).

Phleger CF. 1998. Buoyancy in marine fishes: direct and indirect role of lipids. American Zoologist 38:321-330.

Rickman DD. 2000. Analysis of Water Shock Data and Bubble Screen Effectiveness on the Blast Effect Mitigation Test Series, Wilmington Harbor, North Carolina. Final Report ERDC/SL TR-00-4, U.S Army Corps of Engineers, Engineer Research and Development Center, Vicksburg, Mississippi.

Romano MD, MD Howell, and TA Rien. 2002a. Use of an Artificial Substrate to Capture Eulachon Eggs in the Lower Columbia River. Oregon Department of Fish and Wildlife, Salem, Oregon. Available at http://www.dfw.state.or.us/fish/OSCRP/CRI/publications.asp\#Eulachon (December 2009).

Romano MD, TA Rien, and DL Ward. 2002b. Seasonal presence and diet of white sturgeon at three proposed in-river, deep-water dredge spoil disposal sites in the lower Columbia River. Exhibit K-1 in Final Supplemental Integrated Feasibility Report and Environmental Impact Statement, Columbia River Channel Improvement Project, U.S. Army Corps of Engineers, Portland, Oregon. 
Skalski JR, A Hoffmann, BH Ransom, and TW Steig. 1993. Fixed location hydroacoustic monitoring designs for estimating fish passage using stratified random and systematic sampling. Canadian Journal of Fisheries and Aquatic Sciences 50(6):1208-1221.

Southall BL, AE Bowles, WT Ellison, JJ Finneran, RL Gentry, CR Greene, D Kastak, DR Ketten, JH Miller, PE Nachtigall, WJ Richardson, JA Thomas, and PL Tyack. 2008. Marine mammal noise exposure Criteria: initial scientific Recommendations. Aquatic Mammals 33:411-521.

Stables TB, CJ Perrin, and ML Rosenau. 2005. Acoustic and trawl surveys to locate eulachon aggregations in the lower Fraser River, British Columbia. North American Journal of Fisheries Management 25:675-688.

Tomaro LM, W van der Naald, RR Brooks, TA Jones, and TA Friesen. 2007. Evaluation of Chum and Fall Chinook Salmon Spawning Below Bonneville Dam. DOE/BP-00029512-1, Bonneville Power Administration, Portland, Oregon.

Tomaro LM, W van der Naald, and G Wisler. 2008. Evaluation of Chum and Fall Chinook Salmon Spawning Below Bonneville Dam. Document ID \#P107619, Bonneville Power Administration, Portland, Oregon.

Ward D (ed). 2002. Eulachon studies related to the lower Columbia River channel deepening operations. Exhibit K-2 in Evaluation Report Smelt (revised) in Final Supplemental Integrated Feasibility Report and Environmental Impact Statement for the Columbia River Channel Improvement Project. U.S. Army Corps of Engineers, Portland, Oregon.

Wright DG and GE Hopky. 1998. Guidelines for the Use of Explosives In or Near Canadian Fisheries Waters. Canadian Technical Report of Fisheries and Aquatic Sciences 2107, Fisheries and Oceans Canada, Ottawa, Ontario. Available at http://www.dfo-mpo.gc.ca/oceans-habitat/habitat/watereau/explosives-explosifs/index_e.asp (December 2009).

Yelverton JD, DR Richmond, W Hicks, K Saunders, and ER Fletcher. 1975. The Relationship between Fish Size and Their Response to Underwater Blast. Topical Report DNA 3677T, Defense Nuclear Agency, Washington, D.C. 


\title{
Appendix
}

\author{
Statistical Model for \\ Estimating Take of ESA-Listed Species \\ During Blasting in the Lower Columbia River
}




\section{Appendix \\ Statistical Model for Estimating Take of ESA-Listed Species During Blasting in the Lower Columbia River}

The statistical model described in this appendix was developed and documented by John R. Skalski, Columbia Basin Research, School of Aquatic and Fishery Sciences, University of Washington, Seattle. 


\subsection{Introduction}

The objective of this statistical plan is to present the estimation method that will be used to estimate the take of Endangered Species Act (ESA) listed species by blasting during channel improvement in the Lower Columbia River. Take is defined as the number of fish killed by exposure to impulsive sound caused by blast events. Take will be estimated on a per-blast event basis as well as summed over all blast events that occur during the project.

Take cannot be directly observed and enumerated because of the aquatic environment in which it will occur. Instead, take will be estimated by three elements; the number of fish at risk, a doseresponse function relating sound pressure exposure to the probability of mortality, and the spatial pattern of impulsive sound. The fish density at time of the blast will be integrated over the spatial pattern of exposure and the dose-response function to estimate the number of fish potentially killed by the blast. This estimation process will therefore require the correlation between monitoring efforts to estimate fish density, exposure levels, and the establishment of a mortality function.

\subsection{Statistical Model}

\subsection{Overview}

The fundamental relationship used to estimate take $(T)$ is as follows:

$$
T=\text { fish density } \times \text { area } \times P(\text { mortality }),
$$

where the product of fish density $\times$ area is the number of fish at risk in an area and where the probability of mortality due to impulsive sound exposure measures the degree of risk. In practice, this take equation will be more complex, allowing fish density and probability of mortality to be locationspecific. Thus, total take for a blast event will be the sum of the location-specific estimates of take $T_{i}$, i.e.,

$$
T=\sum_{i=1}^{N} T_{i}=\sum_{i=1}^{N}(\text { fish density })_{i} \times \text { area }_{i} \times P(\text { mortality })_{i} .
$$

The field monitoring will be used to obtain blast event-specific estimates of fish density, which will then be integrated over a mortality function observed from individual blast event sound pressure wave monitoring and an in situ mortality study for juvenile salmonids.

\subsection{Sound Pressure}

Blast sensors located in the region affected by blasting (the "blast zone") will be used to characterize the distribution of impulsive sound as a function of distance from the center of the configuration of explosive charges used for a blast event. The blast sensors in $x$ - $y$ space will be used to 
fit of a simple symmetrical sound propagation model. Should a symmetrical propagation model of the impulsive sound fit the empirical data, a one-dimensional model of the form

$$
s(d)=\alpha d^{-\beta}
$$

will be developed where

$$
\begin{aligned}
& s=\text { sound pressure, } \\
& d=\text { distance from the blast, } \\
& \alpha \text { and } \beta=\text { parameters to be estimated. }
\end{aligned}
$$

If the empirical data suggest a more complex spatial relationship, then a location-specific model will be developed, i.e.,

$$
s\left(l_{i j}\right)
$$

where $l_{i j}$ is the $x-y$ location in the river. In either case, an isopleth map of the sound pressure wave strength will be plotted (Figure 1a). Depth will not be considered because of the size of that dimension is small within the blast region relative to the other dimensions.

\subsection{Mortality Response}

Fish mortality as a function of sound exposure levels for juvenile fish will be developed using in situ fish cage studies and available published data for adult fish. The binomial mortality data from each cage will be modeled as a function of sound exposure levels using a logit-link, binomial error structure, general linear model (other link functions such as proportional hazards may be used if found more appropriate). This "dose-response" model will predict the probability of mortality as a function of sound exposure level (Figure 1b), i.e.,

$$
m(s)
$$

This mortality function will then be used to convert the isopleth map of sound pressure waves to a map of mortality isopleths about the blast zone (Figure 1c), where

$$
m(d)=m(s(d)) .
$$

In other words, a prediction of the probability of fish mortality as a function of distance from the blast zone will be developed (Figure 1c).

\subsection{Fish Density}

To complete the take assessment, the number of fish at risk must be estimated. Active acoustic methods and data for water velocity will be used to estimate the density of fish moving towards the blast zone (Figure 2). This monitoring will be continuously performed for two hours preceding a blast event. The take analysis will assume the fish distribution is a stationary process in the minutes before a 
blast. An average cross-sectional fish distribution will be used to represent the fish densities both above and below the blast zone (Figure 2d). The fluctuations in fish density during the two-hour, pre-event monitoring may be used to propagate a variance estimate.

Acoustic survey methods estimate total fish density for all species within a size range. These species will include both ESA-listed salmonids and non-listed species. To account for only ESA-listed species, the estimated fish density will need to be multiplied by the proportion of acoustic targets that are salmonids $\left(p_{s}\right)$. This estimate of the proportion of ESA-listed species $\left(p_{s}\right)$ will be obtained from the literature and historical monitoring data.

\subsection{Take}

Using the hydroacoustic fish density estimates, along with the mortality curve as a function of distance from the blast, an estimate of take of species I during the $k$ th event is then calculated as follows:

$$
\hat{T}_{k}=\sum_{i=1}^{x} \sum_{j=1}^{y} f_{i j} \cdot m(d \mid i j) \cdot a_{i j} \cdot p_{s}
$$

where

$$
\begin{aligned}
& f_{i j}=\text { fish density in the ijth cell of a grid enveloping the blast area }(i=1, \ldots, x ; j=1, \ldots, y), \\
& a_{i j}=\text { area of the ijth cell }(i=1, \ldots, x ; j=1, \ldots, y), \\
& m(d \mid i j)=\text { probability of fish mortality at distance } d \text { for the ijth cell }(i=1, \ldots, x ; j=1, \ldots, y), \\
& p_{s}=\text { proportion of the hydroacoustically estimated fish density that comprises ESA-listed } \\
& \quad \text { species. }
\end{aligned}
$$

Total take ( $T$ ) across all $K$ blast events is then be calculated as

$$
\hat{T}=\sum_{k=1}^{K} \hat{T}_{k} .
$$



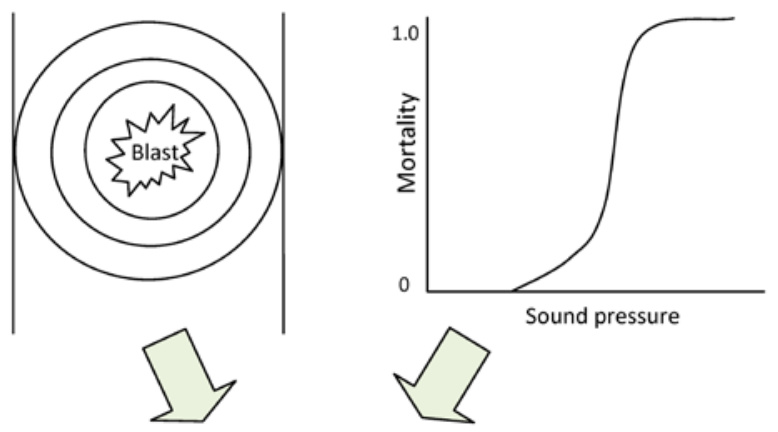

c. Isopleths of mortality probability

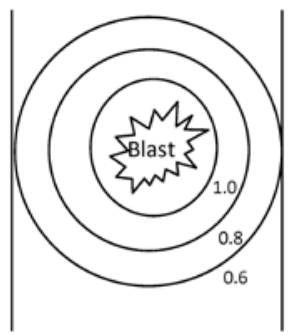

d. Fish density

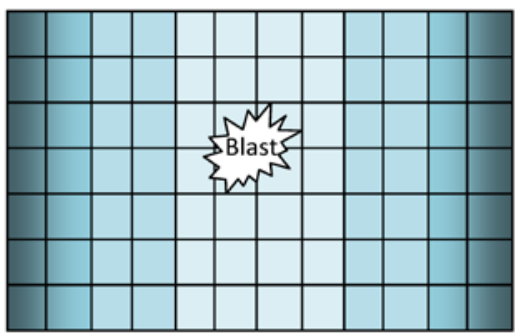

e. Fish deaths

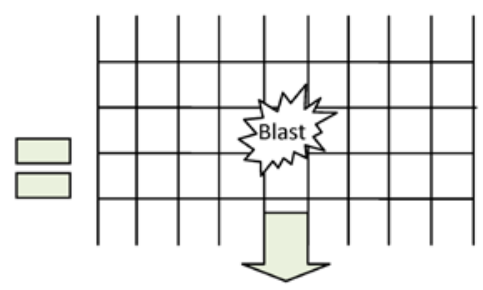

$\Sigma$ over area $=$ Fish take

Figure 1. Schematic of how fish take will be estimated from information on sound pressure profile, mortality curves, and fish density. The pressure field (a) will be combined with the mortality function (b) to produce isopleths of mortality probabilities (c) about the blast zone. Then the mortality isopleths (c) will be combined with the information on fish density (d) to calculated expected number of dead (e). 


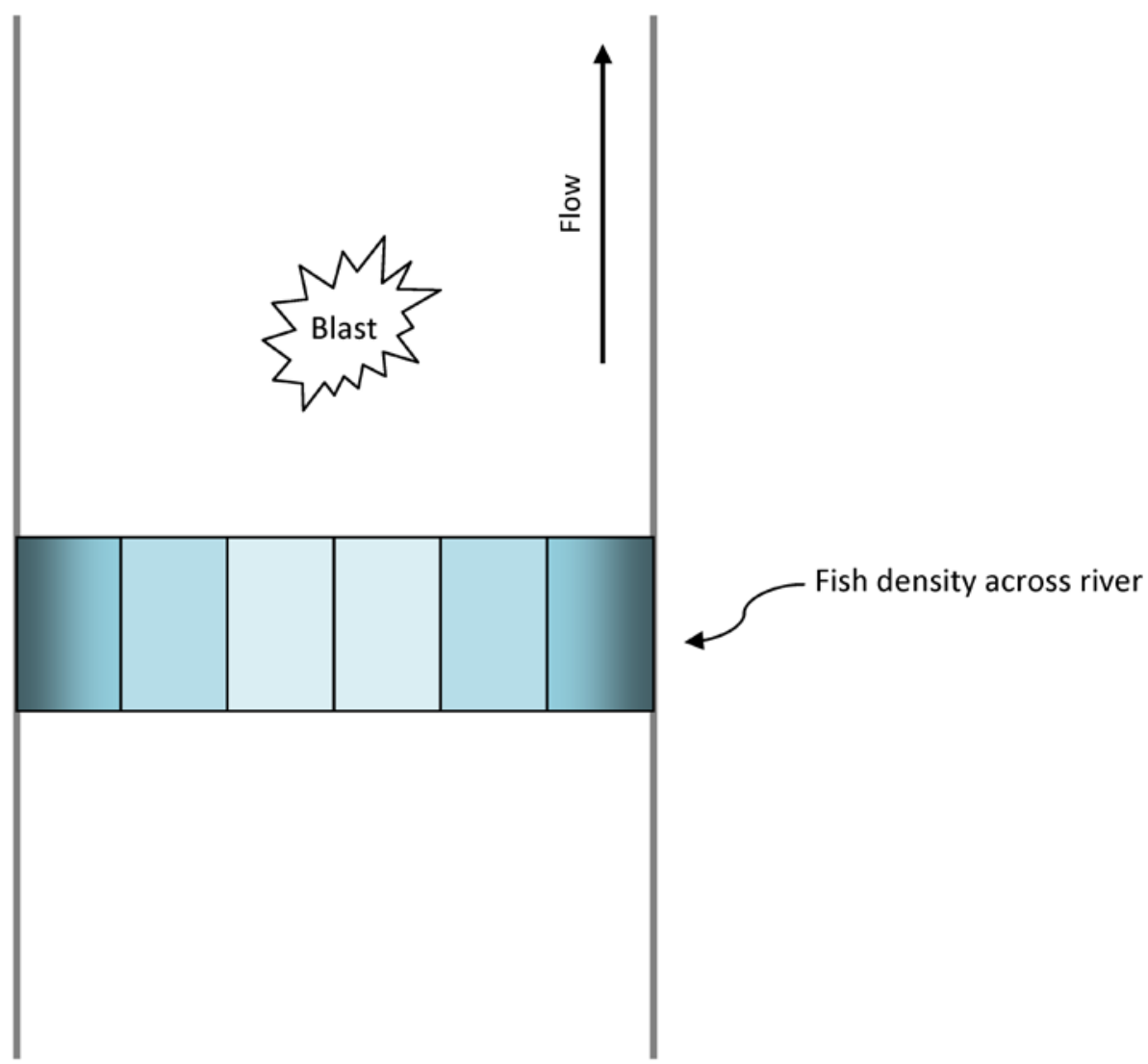

Figure 2. Schematic of cross-sectional fish density estimated over time upstream of blast area. For illustrative purposes only, fish density is shaded to indicate higher densities near shorelines. This crosssectional density profile will be applied above and below the blast zone when estimating take (see Figure 1d). 


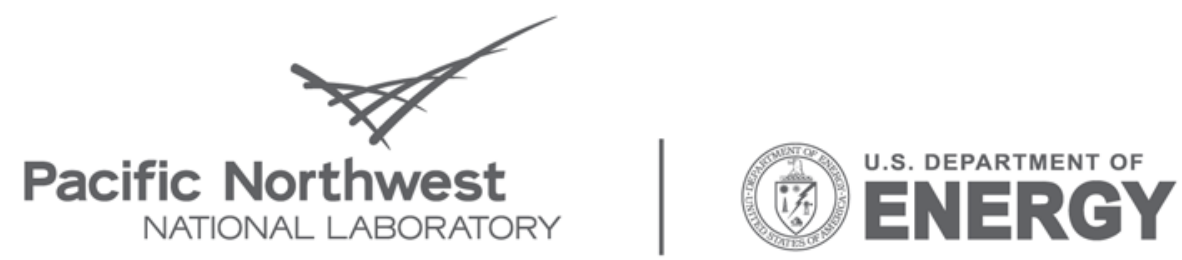

Proudly Operated by Battelle Since 1965

902 Battelle Boulevard

P.O. Box 999

Richland, WA 99352

1-888-375-PNNL (7665)

www.pnl.gov 